\title{
Transient Receptor Potential Channels and Inflammatory Bowel Disease
}

\author{
Yiding Chen ${ }^{1,2}$, Jingxi Mu ${ }^{1,2}$, Min Zhu ${ }^{1,2}$, Arjudeb Mukherjee $^{3}$ and Hu Zhang ${ }^{1,2 *}$ \\ ${ }^{1}$ Department of Gastroenterology, West China Hospital, Sichuan University, Chengdu, China, ${ }^{2}$ Centre for Inflammatory \\ Bowel Disease, West China Hospital, Sichuan University, Chengdu, China, ${ }^{3}$ West China School of Medicine, Sichuan \\ University, Chengdu, China
}

OPEN ACCESS

Edited by:

Santiago Partida Sanchez, Nationwide Children's Hospital,

United States

Reviewed by:

Alessandro Alaimo, University of Trento, Italy

Daniel Keszthelyi,

Maastricht University, Netherlands

*Correspondence: Hu Zhang zhanghu@scu.edu.cn

Specialty section:

This article was submitted to

Molecular Innate Immunity, a section of the journal

Frontiers in Immunology

Received: 18 November 2019

Accepted: 23 January 2020

Published: 20 February 2020

Citation:

Chen Y, Mu J, Zhu M, Mukherjee A and Zhang $H$ (2020) Transient

Receptor Potential Channels and Inflammatory Bowel Disease.

Front. Immunol. 11:180

doi: 10.3389/fimmu.2020.00180
The transient receptor potential (TRP) cation channels are present in abundance across the gastrointestinal (Gl) tract, serving as detectors for a variety of stimuli and secondary transducers for G-protein coupled receptors. The activation of TRP channels triggers neurogenic inflammation with related neuropeptides and initiates immune reactions by extra-neuronally regulating immune cells, contributing to the GI homeostasis. However, under pathological conditions, such as inflammatory bowel disease (IBD), TRP channels are involved in intestinal inflammation. An increasing number of human and animal studies have indicated that TRP channels are correlated to the visceral hypersensitivity (VHS) and immune pathogenesis in IBD, leading to an exacerbation or amelioration of the VHS or intestinal inflammation. Thus, TRP channels are a promising target for novel therapeutic methods for IBD. In this review, we comprehensively summarize the functions of TRP channels, especially their potential roles in immunity and IBD. Additionally, we discuss the contradictory findings of prior studies and offer new insights with regard to future research.

Keywords: transient receptor potential channels, gastrointestinal tract, neurogenic inflammation, immune cells, inflammatory bowel disease

\section{INTRODUCTION}

Inflammatory bowel disease (IBD) is a chronic relapsing GI inflammatory disorder, comprising of Crohn's disease (CD) and ulcerative colitis (UC). It is acknowledged that IBD is related to inappropriate immunity, commensal bacteria, genetics, and environmental factors. The exact pathogenesis of IBD, however, remains unknown (1). Nowadays, various receptors in the gastrointestinal (GI) tract are proposed to play a role in the pathophysiology of IBD, amongst which transient receptor potential (TRP) ion channels have been identified and are considered to be potentially effective. TRP channels are polymodal ion channels that serve as sensors for chemical noxious and physical stimuli. These channels are widely distributed in the GI tract and exert various effects, contributing to the somatic and visceral nociception and the maintenance of physiological function of the GI tact (2). The activation of TRP channels can evoke neurogenic inflammation, namely the inflammation initiated by the local release of immunomodulatory neuropeptides, including calcitonin-gene-related peptide (CGRP) and substance P (SP) released by unmyelinated afferent neurons $(3,4)$. Some TRP channels are also expressed in multiple immune cells, and are primarily responsible for modulating actions, such as cytokine release, cell migration, and phagocytic activity (2). Therefore, numerous studies have indicated that TRP channels are mainly 
involved in the visceral hypersensitivity (VHS) and immune pathogenesis of IBD due to their comprehensive functions of sensors and immunomodulators. Different subtypes of TRP channels seem to have distinct effects. Here, we briefly review the correlation between TRP channels and IBD with a focus on TRPV1, TRPA1, TRPV4, TRPM2, and TRPM8, which have been documented to be the most relevant TRP channels in IBD.

\section{TRP CHANNELS IN THE GI TRACT AND RELATED NEUROPEPTIDES}

In the GI tract, TRP channels are mainly expressed on the extrinsic primary afferent nerves with some on epithelial, endocrine cells, and intrinsic enteric neurons $(5,6)$. Intriguingly, 97\% of TRPA1-positive $\left(\mathrm{TRPA}^{+}{ }^{+}\right.$) afferents co-express TRPV1, and $30 \%$ of the TRPV1-positive $\left(\mathrm{TRPV1}^{+}\right.$) neurons co-express TRPA1, hinting at the potential interaction between the two channels $(5,7)$. Capsaicin is a significant agonist for TRPV1 with an exquisite selectivity and allyl isothiocyanate (AITC), the pungent ingredient in garlic, is the prototypical agonist for TRPA1 $(8,9)$. TRPV4 colocalizes with TRPV1, TRPA1, and protease-activated receptors 2 (PAR-2) in the GI tract, in response to strong acidosis, hypotonicity, warmth, and mechanical stimuli $(10,11)$. TRPM2 is sensitive to heat stimulus while TRPM8 is essential to cold-induced pain (12). Most of TRP channels are non-selective cation channels and show the permeability to calcium ion $\left(\mathrm{Ca}^{2+}\right)$. Upon stimulation, TRP channels in afferents can lead to autonomic reflex responses by transmitting signals to the central nervous system. Meanwhile, TRP channels can transduce sensory signal of G-protein coupled receptors (GPCRs) based on the phosphorylation sites in $\mathrm{N}$-terminus for serine and threonine protein kinases, such as protein kinase A (PKA) and protein kinase $\mathrm{C}(\mathrm{PKC})(11,13)$.

Additionally, TRP channels in the GI tract can mediate the crosstalk between the nervous and immune systems by modulating the release of neuropeptides. TRPV1, TRPA1, and TRPV4 are especially often found to colocalize with CGRP and SP $(6,14)$.

CGRP, which is generated from the alternative RNA processing of the gene for calcitonin, serves as a potent peptide vasodilator and is involved in the transmission of nociception (15). CGRP plays a protective role in the inflammation and inhibits the capacity of immune cells. For dendritic cells (DCs) and macrophages, CGRP could restrain their ability in the presentation of antigens and the secretion of pro-inflammatory cytokines, such as tumor necrosis factor alpha (TNF- $\alpha)(16,17)$. CGRP also downregulated DCs' responses to Toll-like receptor 4 (TLR4), a receptor for lipopolysaccharides (LPS) which is an abundant outer wall glycolipid of Gram-negative bacteria (18). CGRP can exert an inhibitory effect on the activation and chemotaxis of neutrophils (19), and inhibit neutrophilmediated killing of bacteria mainly through suppressing the activity of the bactericidal enzyme myeloperoxidase (MPO) in a dose-dependent manner (20). CGRP was found to restrain group 2 innate lymphoid cells proliferation and type 2 innate immune responses (21), and be required for the induction of protective innate type 17 immunity after the activation of cutaneous TRPV1 ${ }^{+}$neurons (22). Furthermore, CGRP could induce the upregulation of interleukin (IL)- 10 and was beneficial in preserving mucosal integrity and limiting tissue damage (16). These observations demonstrate the negative regulatory role of CGRP in innate immunity and the benefits of CGRP in the GI tract. Conversely, GRCP was reported to be capable of stimulating T-cell migration and promoting the release of interferon gamma (IFN- $\gamma$ ) and IL-2 from T-helper cells $(23,24)$. In IBD patients, the expression of CGRP in the colonic mucosa was significantly increased and was closely associated with the severity of disease $(25,26)$. Therefore, CGRP might also play a part in the pro-inflammatory process.

SP belongs to tachykinin family. The receptor for SP is the neurokinin 1 receptor (NK-1R) (15). Similar to GCRP, SP serves as a potent vasodilator and the SP-induced vasodilatation is based on nitric oxide (NO) release (27). Of interest, high-dose CGRP was reported to restrain the SP-evoked vasodilation but facilitate SP-evoked plasma protein extravasation (28), suggesting a crosstalk between CGRP and SP. The expression of SP and NK$1 \mathrm{R}$ has been well-documented in DCs, monocytes, eosinophils, neutrophils, mast cells, natural killer cells, and T cells, enabling SP to regulate functions of different types of immune cell (29). SP also modulated the immune response to microbial infection (29). It was recently demonstrated that SP could promote the migration and activation of mast cells, inducing the release of multiple pro-inflammatory cytokines and chemokines (30). Noteworthy, SP directly caused the secretion of IL-8 in human colonic epithelial cell lines (31), hinting at the potential proinflammatory role of SP in intestine. SP was detected to be elevated in tissue extracts from the colon and rectum of IBD patients, and the level of SP was correlated with disease activity (32). However, in animal studies, SP ameliorated dextran sulfate sodium (DSS)-induced colitis by promoting the enrichment of M2 macrophages and regulatory $\mathrm{T}$ cells, or maintaining barrier structure and regulating immune response $(33,34)$. Such results remind us of the possible protective effect of SP in colitis. Taking these contradictory observations with regard to the properties of CGRP and SP into consideration, we can conclude that the neurogenic inflammation triggered by TRP channels has bidirectional functions on immunity and colitis. However, the exact function of neuropeptides on a certain physical or pathological condition has not yet been discovered and further studies are required.

\section{TRP CHANNELS IN IMMUNE CELLS}

Besides the roles in nervous system of the GI tract, TRP channels are also expressed in immune cells and directly contribute to immune responses. In bone marrow-derived macrophages, the TRPV1 expression was increased and intracellular $\mathrm{Ca}^{2+}$ transients were triggered after oxidized low-density lipoprotein (ox-LDL)-stimulation (35). TRPV1 could dose-dependently modulate the level of inducible NO synthase in stimulated peritoneal macrophages through the inhibition of nuclear factor kappa B (NF-KB), thus influencing the secretion of 
pro-inflammatory cytokines involved in this pathway (2). In a sepsis model, the LPS-stimulated peritoneal macrophages showed an impaired phagocytosis when TRPV1 was knockout (36), suggesting the putative role of TRPV1 to potentiate macrophages. In $\mathrm{CD} 4{ }^{+} \mathrm{T}$ cells, TRPV1 was associated with $\mathrm{T}$ cell receptor (TCR) and facilitated TCR-induced $\mathrm{Ca}^{2+}$ inflow (37), and the activity of $\mathrm{CD}^{+}{ }^{+} \mathrm{T}$ cells was impaired via the inhibition of TRPV1 (38). The activation of TRPV1 was also reported to enhance leukocyte rolling and adhesion (39). These data indicated the possible pro-inflammatory properties of TRPV1 in immune cells. Intriguingly, TRPV1 activation can trigger the production of the endocannabinoid anandamide, which increases the level of regulatory CX3CR1 (hi) macrophages in the gut and enhances their immunosuppressive activity (40). In DCs, TRPV1 mediates the downregulation of TLR4/NF- $\mathrm{B}$ signaling pathway that leads to the maturation of DCs (41). A recent research concerning lethal Staphylococcus aureus pneumonia stated that the activation of TRPV $1^{+}$nociceptors by capsaicin could suppress cytokine release, inhibit the recruitment and surveillance of neutrophils, and alter lung $\gamma \delta$ T cell numbers; thus impairing lung bacterial clearance (42). As discussed above, TRPV1 is an important immunomodulator that regulates the activation and function of immune cells.

As for TRPA1, its expression was increased in stimulated $\mathrm{T}$ cells, and TRPA1 was vital for the $\mathrm{T}$ cell activation and release of cytokines like TNF- $\alpha$, IFN- $\gamma$ and IL-2 (43). TRPA1 also expresses in mast cells and DCs (44). In TRPA1-knockout $\left(\right.$ Trpa1 $\left.1^{-/}\right)$mice, mast cells, leukocytes, and $\mathrm{T}$ cells, together with the expression of IL-1 $\beta$, IL-6, IL-17, IL-22, and IL-23 were decreased in the lesions of skin (45), indicating the ability of TRPA1 to induce inflammation through these immune cells. In addition to its pro-inflammatory function, the activation of TRPA1 could suppress the pro-inflammatory effect of LPSstimulated peritoneal macrophages by decreasing the level of $\mathrm{NO}$, which is an abundant pro-inflammatory mediator (46). Taken together, TRPA 1 has the ability to regulate immune cells in diverse manner. The crosstalk between TRP channels and bacteria is noteworthy. It was discovered that LPS interacted with TLR4 on the TRPV1 ${ }^{+}$afferent neurons. This then activated or sensitized TRPV1 via its phosphorylation binding sites through PKC, thus resulting in an increased release of CGRP $(17,47)$. Antagonists for TRPV1 and CGRP could reverse LPS-induced motility disturbance of the intestine (48). Another study showed that a probiotic bacterium named Lactobacillus reuteri and its condition medium dose-dependently reduced the capsaicin- and distension- evoked firing of jejunal spinal afferents in mice (49), revealing the engagement of afferents in bacteria-induced GI sensory-motor dysfunction. TRPA1 in nociceptive neurons could be sensitized by LPS in a TLR4-independent manner during inflammation, causing pain, CGRP release, and vasodilation (50). Therefore, it was hypothesized that TRP channels may be able to directly or indirectly interact with microbiota or their products in the gut, thus influencing the release of neuropeptides and contributing to the maintenance of gut homeostasis.

The activation of TRPV4 increased intracellular $\mathrm{Ca}^{2+}$ concentration in LPS-treated macrophages and potentiated macrophage (51), while downregulation of TRPV4 subsequently impaired the phagocytosis of macrophages (52). In neutrophils, TRPV4 was essential for inflammatory responses, such as the neutrophil adhesion, chemotaxis, and formation of reactive oxygen species (53). TRPV4-mediated $\mathrm{Ca}^{2+}$ influx in $\mathrm{T}$ cells was also capable of inducing the proliferation of $\mathrm{T}$ cells and the secretion of TNF- $\alpha$, IFN- $\gamma$, and IL-2 in vitro (54). Recent data revealed that TRPV4 could promote the phagocytosis of mouse CD11c ${ }^{+}$bone marrow-derived cells (55). These findings clearly highlight the critical pro-inflammatory role of TRPV4 in immune cells.

Regarding TRPM2, it was demonstrated that the lack of this channel in LPS-stimulated monocytes cell line reduced the release of TNF- $\alpha$, IL-6, IL-8, and IL-10 (56). TRPM2associated $\mathrm{Ca}^{2+}$ signaling was essential in the transmigration and cytotoxicity of neutrophils $(57,58)$, the proliferation of T cells, and the release of pro-inflammatory cytokines (59). For TRPM8, the activation by menthol in murine peritoneal macrophages increased IL-10 expression and decreased TNF- $\alpha$ release, thus exerting an anti-inflammatory effect (60). TRPM8-knockout $\left(\operatorname{Trpm} 8^{-/-}\right)$peritoneal macrophages exhibited an impaired phagocytic activity while the phagocytosis was enhanced in WT peritoneal macrophages after the activation of TRPM8 (60). Consistently, the activation of TRPM8 was reported to restrain the release of pro-inflammatory mediators in monocytes and lymphocytes, and $\operatorname{Trpm} 8^{-/-} \mathrm{CD} 11 \mathrm{c}^{+} \mathrm{DCs}$ showed hyperinflammatory responses to TLR-stimulation (61, 62). In T cells, the inhibition of TRPM8 suppressed murine T-cell activation and the release of IL-2 and IL-6 (63). Overall, TRPM2 appears to potentiate inflammatory effects of immune cells while TRPM8 often performs anti-inflammatory roles.

\section{TRP CHANNELS IN INFLAMMATORY VISCERAL HYPERSENSITIVITY OF IBD}

Due to their immunomodulatory function via neuropeptides and immune cells, TRP channels are associated with GI immunity and inflammation. Notably, it is found that their expression has been altered in IBD patients and colitis models (Table 1), suggesting an involvement of TRP channels in IBD. In particular, IBD patients are associated with a visceral hypersensitivity (VHS), which is featured of an aberrant and chronic visceral pain $(5,12)$. As visceral nociceptors, TRP channels are proposed to be responsible for VHS in IBD. Since TRP channels serve as secondary transducers for GPCRs, some mediators that act on GPCRs subsequently activate or sensitize TRP channels, resulting in aberrant sensation. Through this mechanism, pro-inflammatory mediators secreted during colitis, such as bradykinin, serotonin (5-hydroxytryptamine, 5-HT), cytokines, adenosine triphosphate, prostaglandins, and epinephrine can lead to the inflammatory VHS (5). A number of researches have been conducted to explore the definite role of TRP channels in colitis and VHS (Table 2).

\section{TRPV1}

TRPV1 channel is closely linked to VHS. It was found that some patients with quiescent IBD still complained about 
TABLE 1 | The expression of TRP channels in colonic tissue of IBD patients and colitis models.

\begin{tabular}{|c|c|c|c|c|c|}
\hline & TRPV1 & TRPA1 & TRPV4 & TRPM2 & TRPM8 \\
\hline \multicolumn{6}{|l|}{ IBD patients } \\
\hline UC & $\begin{array}{l}\text { UP (64-68) } \\
\text { NS (69) } \\
\text { DOWN }(70,71)\end{array}$ & UP (68) & $\begin{array}{l}\text { UP }(70,72) \\
\text { NS }(73)\end{array}$ & NA & NA \\
\hline CD & $\begin{array}{l}\text { UP }(64-66) \\
\text { DOWN }(68,71)\end{array}$ & $\begin{array}{l}\text { UP } \\
(68,71,74,75)\end{array}$ & $\begin{array}{l}\text { UP }(72,76) \\
\text { NS }(73)\end{array}$ & NA & UP (77) \\
\hline DSS-treated mice & $\begin{array}{l}\text { UP }(68,78-80) \\
\text { NS }(71)\end{array}$ & UP (71) & UP $(73,81)$ & NA & $\operatorname{UP}(77,82)$ \\
\hline DSS-treated rats & UP (83) & NA & NA & NA & NA \\
\hline TNBS-treated mice & UP (84) & NA & UP (72) & NA & $\operatorname{UP}(77,82)$ \\
\hline DNBS-treated mice & NA & UP (85) & NA & NA & NA \\
\hline TNBS-treated rats & $\begin{array}{l}\text { UP (86) } \\
\text { NS (87) }\end{array}$ & UP $(88,89)$ & NA & UP (90) & NA \\
\hline
\end{tabular}

UC, ulcerative colitis; CD, Crohn's disease; DSS, dextran sulfate sodium; TNBS, 2,4,6-trinitrobenzenesulfonic acid; DNBS, dinitrobenzene sulfonic acid; UP, upregulated; DOWN, downregulated; NS, no significant difference; NA, not available.

TABLE 2 | The function of TRP channels in VHS of colitis models.

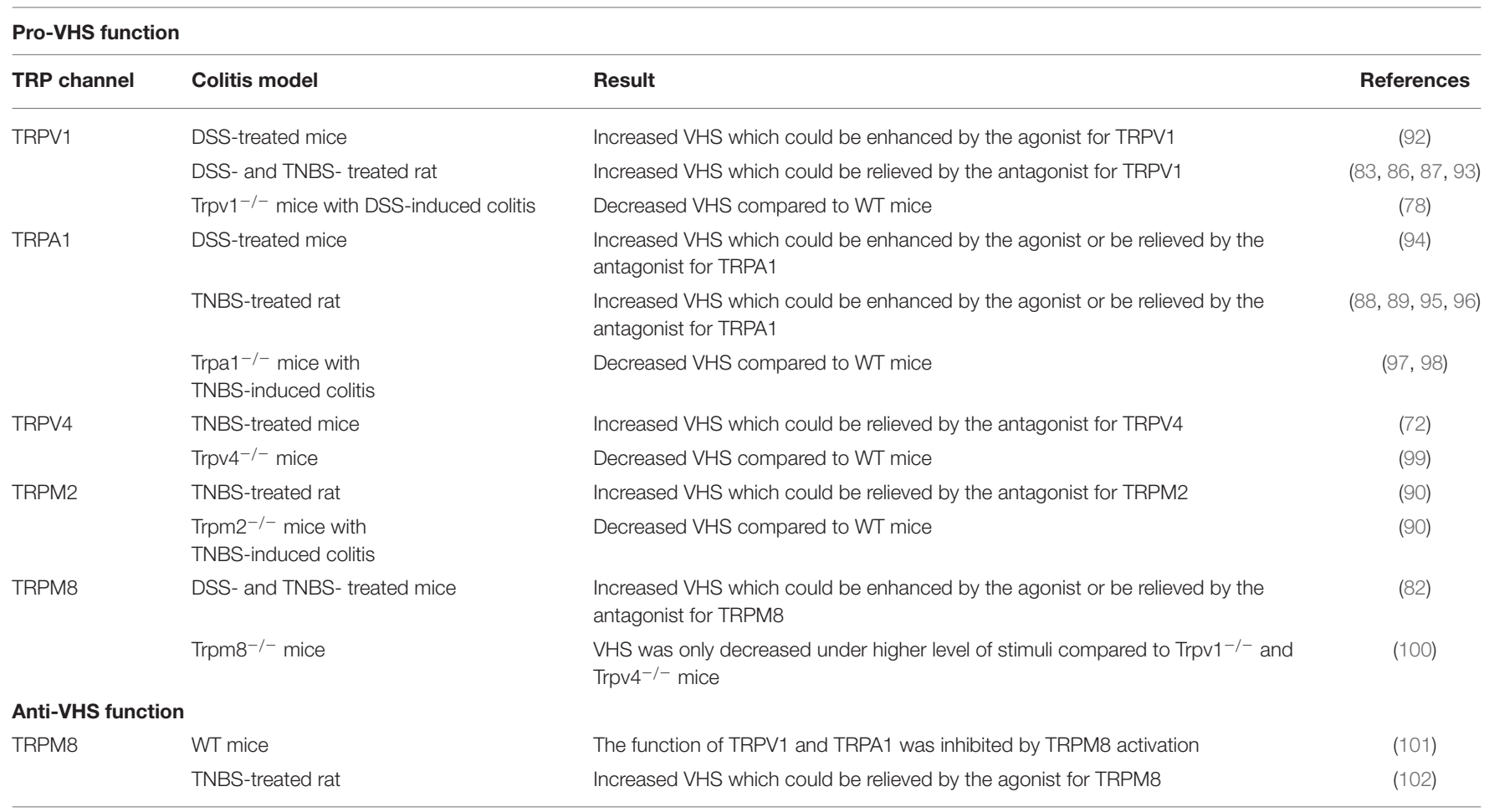

VHS, visceral hypersensitivity; DSS, dextran sulfate sodium; TNBS, 2,4,6-trinitrobenzenesulfonic acid; WT, wild-type.

abdominal pain, and the severity of their symptoms was correlated to the increased TRPV $1^{+}$fibers in colonic mucosa (64). In animal studies, the behavioral responses to intracolonic capsaicin administration and the expression of spinal cord neuronal c-Fos, which is a marker of neuronal excitation, were increased in DSS-treated mice (92). Yang et al. (83) reported that an oral administration of curcumin, which is clinical valuable for the treatment of IBD (103), in DSS-treated rats could significantly ameliorate visceral hyperalgesia through inhibiting phosphorylation of TRPV1, indicating a nociceptive effect of TRPV1. Likewise, Phillis et al. (93) revealed that TRPV1 antagonist remarkably reduced the mechanosensory response to the stimulus in a dose-dependent manner in rats with DSS-induced colitis. Visceral hyperalgesia and increased 
visceromotor response (VMR) were also confirmed in rats with 2,4,6-trinitrobenzenesulfonic acid (TNBS)-induced colitis (86, 87), while TRPV1 antagonist (JYL1421) could prevent and relieve the VHS (86). Additional studies exhibited that TRPV1-knockout $\left(\operatorname{Trp} v 1^{-/-}\right)$mice conferred a resistance to colorectal distension $(78,104)$, and VHS was enhanced by inflammatory mediators, such as bradykinin, 5-HT, histamine, and prostaglandin E2 (PGE2) in WT mice but not in Trpv1-/mice (12). SP was demonstrated to enhance the sensitivity and function of TRPV1 in DSS-induced colitis and in vitro (78), suggesting the engagement of neuropeptides in VHS. Noteworthy, the augmented activity of pelvic nerve afferents after TRPV1 activation in DSS-treated rats was more prominent on the first day post DSS-treatment, in comparison to the eighth day (92). Similarly, the levels of TRPV1 and TRPA1 messenger RNA (mRNA) in mice were upregulated in mustard oil (MO)induced colitis within $6 \mathrm{~h}$ but decreased 24- and 72-h after MO-injection (91). Therefore, it can be hypothesized that the excitatory mechanism modulated by TRPV1 mainly particulate during early stage of experimental colitis.

\section{TRPA1}

TRPA1 could contribute to colorectal contraction and enhanced VMR to intracolonic AITC, which were detectable in TNBSinduced colitis. These actions could be suppressed by intrathecal pretreatment with a TRPA 1 antisense oligodeoxynucleotide, and were absent in Trpa1 ${ }^{-/-}$mice $(88,89,97,98)$. Likewise, AITC enhanced the sensitivity of colon and the expression of cFos in spinal cord of DSS-treated mice (94). During TNBSinduced colitis, the production of hydrogen peroxide $\left(\mathrm{H}_{2} \mathrm{O}_{2}\right)$ was enhanced due to the infiltration of white blood cells and the presence of oxidative stress. The increased $\mathrm{H}_{2} \mathrm{O}_{2}$ then activated TRPA1 and led to the hypersensitivity of VMR (95). The aberrant GI motility might result from the effects of PGE2 induced by TRPA1 activation (105). Similarly, inflammatory mediators, such as bradykinin and 5-HT could lead to an increased visceral mechano-sensitivity in a TRPA1-associated manner $(97,106)$. These data suggest a close link between TRPA1 and proinflammatory cytokines, both of which contribute to visceral hyperalgesia. Of interest, Vermeulen et al. (96) reported that a combined application of antagonists for TRPV1 and TRPA1 could reduce the VMR more effectively in TNBS-induced colitis, in comparison to targeting either TRPV1 or TRPA1 alone. Such evidence appears to provide an inspiring therapeutic method for inflammatory VHS.

\section{TRPV4}

TRPV4 is vital for a mechanically-evoked visceral pain in the GI tract (76). It was found that TRPV4 co-expressed with PAR-2 and pretreatment of PAR-2 agonist enhanced TRPV4 activity and hypersensitivity, while the inhibition of PKA and PKC restrained this effect $(99,107)$. Also, 5-HT and histamine improved TRPV4-induced hypersensitivity for colorectal distention in mice (108). These results indicate the responses of TRPV4 to inflammatory mediators through GPCR signaling pathway. A selective blockade of TRPV4 was subsequently evident to alleviate intestinal inflammation and pain in TNBS-treated mice (72).
Therefore, the pro-hypersensitivity function of TRPV4 during colitis is relatively clear.

\section{TRPM2}

In TNBS-induced rat colitis, the VMR was enhanced and could be ameliorated by an oral administration of TRPM2 antagonist (econazole) (90). However, in TRPM2-knockout (Trpm2-/-) mice, the TNBS-induced VMR was less severe compared to WT mice (90), showing a potential facilitating role of TRPM2 in VHS.

\section{TRPM8}

Menthol, serving as the agonist for TRPM8, has been applied to relieve abdominal discomfort and pain in traditional Chinese medicine, suggesting that TRPM8 activation can diminish visceral pain perception (12). In TNBS-induced colitis, the colonic mechano-hypersensitivity was remarkably suppressed by a combined adoption of peppermint and caraway oil, which are agonists for TRPM8 (102). Harrington et al. (101) demonstrated that TRPM8 activation restrained the downstream chemosensory and mechanosensory actions of TRPA1 and TRPV 1 to agonists in colonic afferents, stating the potential function of TRPM8 for inhibiting TRPV 1 and TRPA1. In contrast, it was showed that the TRPM8 agonist (WS-12) enhanced visceral pain response while a pretreatment of TRPM8 antagonist inhibited the hypersensitivity (82). Another study reported that in $\operatorname{Trpm} 8^{-/-}$mice, VMR only decreased when the pressure level of colorectal distension was quite high; but in $\operatorname{Tr} p v 1^{-/-}$and $\operatorname{Tr} p v 4^{-/-}$mice, VMR was remarkably decreased in all pressure ranges (100). Of note, both bradykinin and histamine were found to suppress TRPM8 mainly via the G-protein subunit $\mathrm{G} \alpha$ which inhibited ion channel activity of TRPM8 (109), indicating the ability of inflammatory mediators to desensitize TRPM8 and inhibit its function. Such a mechanism may account for the TRPM8-associated enhancedVHS during inflammation.

\section{TRP CHANNELS IN IMMUNE PATHOGENESIS OF IBD}

In addition to the roles in inflammatory VHS, the potential engagement of TRP channels in the immune pathogenesis of IBD has been highlighted in human and animal studies (Table 3).

\section{TRPV1}

The TRPV $1^{+}$fibers were increased in the colonic mucosa of IBD patients, along with non-neuronal TRPV1 immunoreactivity (65, 66). Further study confirmed an increased expression of TRPV1 in inflamed tissue of active UC patients compared with noninflamed tissue, being associated with a relapse and continuous activity of disease $(64,67)$. However, a downregulated expression of TRPV1 was also revealed in colonic biopsies from UC and CD patients $(68,70,71)$, and Rizopoulos et al. (70) found no significant correlation between TRPV1 expression and clinical features in UC patients. In experimental colitis models, TRPV1 expression was also found to be altered $(68,78-80,83,84,86)$ (Table 1). Kihara et al. (110) subcutaneously injected noxiousdose capsaicin into neonatal rats to chemically denervate the TRPV1 channel, revealing that the denervated rats exhibited a 
TABLE 3 | The function of TRP channels in pathophysiology of colitis models.

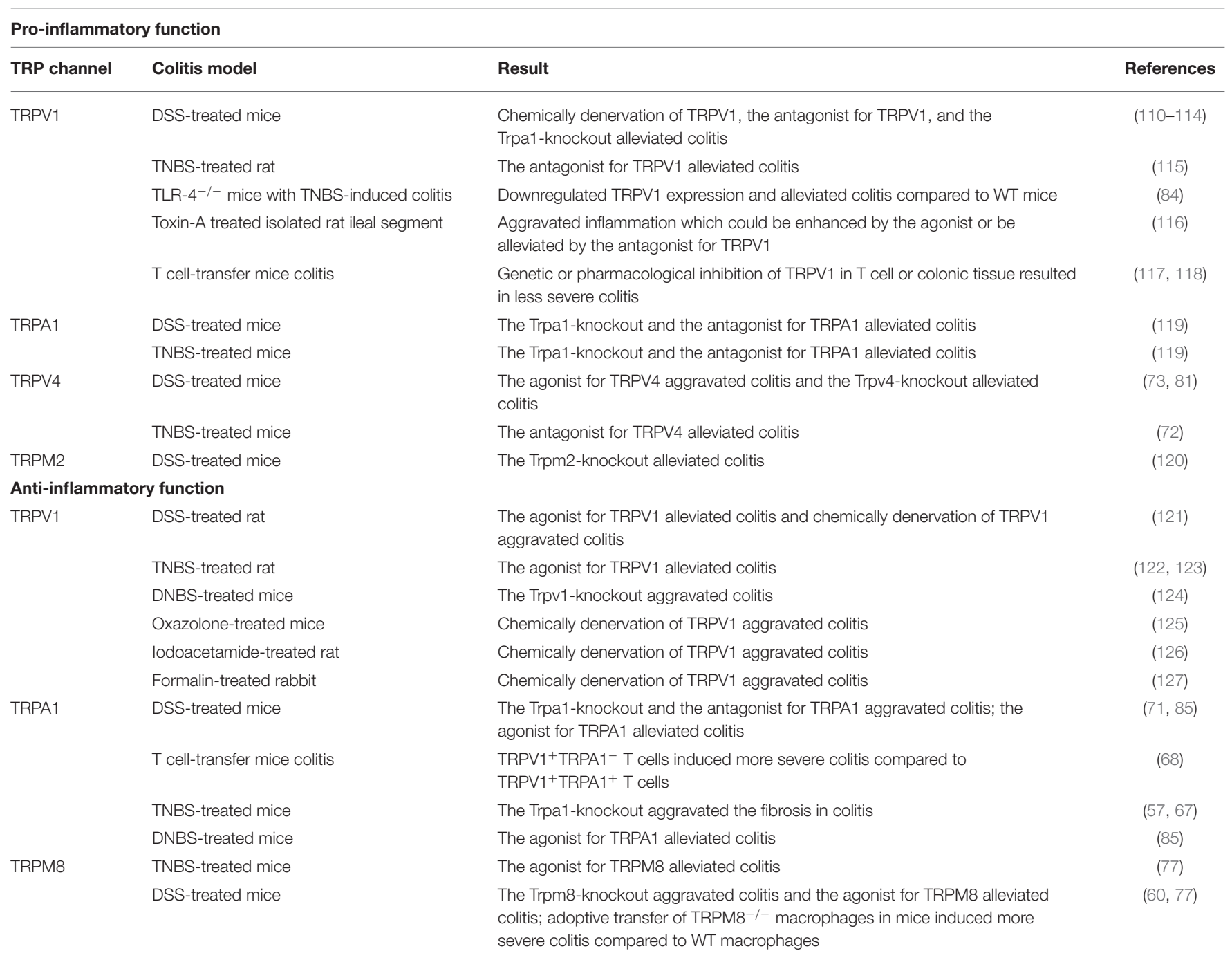

DSS, dextran sulfate sodium; TNBS, 2,4,6-trinitrobenzenesulfonic acid; DNBS, dinitrobenzene sulfonic acid; WT, wild-type.

lower severity of DSS-induced colitis compared with the control group. Similarly, it was showed that an oral administration of capsazepine (CPZ), which is a specific antagonist for TRPV1, significantly reduced the overall macroscopic epithelial damage in mice colonic tissue after intraperitoneal DSS-administration (111). In $\operatorname{Trp} v 1^{-/-}$mice, the DSS-induced colitis was less severe $(112,113)$, and a DSS-associated upregulation of SP-positive fibers was reduced (114), demonstrating a crosstalk between TRPV1 and neurogenic inflammation in colitis. In addition, it was reported that rats with TNBS-induced colitis exhibited a reduction of macroscopic damage score and MPO activity after CPZ enema (115). Recent data pointed that TLR4-knockout mice showed a less inflammatory infiltration and a decreased expression of TRPV1 in TNBS-induced colitis, indicating one possible function of TLR4 for mediating TRPV1 signaling under inflammatory conditions (84). As for other animal models, McVey et al. (116) suggested that an intraluminal administration of capsaicin in isolated ileal segments of rats led to an intestinal inflammation which could be reduced by CPZ. In T-cell-transfer colitis model, the activation of TRPV1 tended to exacerbate the intestinal inflammation, while the colitis was less severe when the TRPV1 in T cell was genetically or pharmacologically inhibited. The pro-inflammatory property of TRPV1 in T cells may be associated with the release of TNF- $\alpha$, IFN- $\gamma$, IL2, IL-4, IL-10, and IL-17 (117). In another study, capsaicininduced TRPV $1^{+}$fibers-denervation ameliorated the intestinal inflammation in the T-cell-transfer colitis model (118), but the suppressive effect of noxious-dose capsaicin pretreatment only existed in 7-8 weeks old mice for several weeks after T-cell transfer, and these mice eventually developed colitis (128). It was further revealed that the severity of TNBS-induced colitis in the TRPV ${ }^{+}$fibers-denervated rats was drastically increased within 3-7 days after TNBS administration. Nevertheless, no significant difference of the colitis was found between denervated rats and normal rats in 14-21 days (129), reinforcing the concept that $\mathrm{TRPV}^{+}$fibers are involved in the early steps of colitis. Taken 
together, these reports indicate that the activation of TRPV1 in colon is essential for the propagation of intestinal inflammation, and it might be a proximal event in the inflammatory process.

Noteworthy, several publications have reported the protective effects of TRPV1 in experimental colitis. It was exhibited that a local application of capsaicin and exogenous administration of CGRP ameliorated the colonic lesions in TNBS-induced rat colitis $(122,123)$. Massa et al. (124) stated that Trpv1 $1^{-/-}$mice exhibited a worse outcome of colitis and lower expression of anti-inflammatory neuropeptides, such as vasoactive intestinal peptide (VIP) and pituitary adenylate cyclase-activating peptide (PACAP), while the NF-кB and STAT3 signaling pathways were demonstrated to be enhanced (130). Moreover, TRPV1 was reported to restrain the initiation and progression of colon cancer (130). In DSS-treated rats, a daily administration of capsaicin was able to reduce the severity of colitis, while a desensitization of TRPV $1^{+}$-fibers dramatically worsened the inflammation (121). A protective role of TRPV1 was also identified in oxazoloneinduced mice colitis, iodoacetamide-induced rat acute colitis, and formalin-induced rabbit acute colitis (125-127). The rather ambiguous findings concerning the roles of TRPV1 in colitis required further scrutiny.

Intriguingly, the expression of the TRPV 1 was increased in the distal colon and rectum compared to the proximal colon in mice, and similar proximodistal gradient of CGRP/SP was detected (79, 131). Considering the anatomical distribution pattern of UC that often exhibits an ascending inflammation from rectal to proximal colon (4), the increased activity of TRPV1 and neuropeptides in distal colon might give rise to the increased susceptibility of distal colon to colitis and promote the spread of ascending inflammation. Such observations hint at the correlation between the diverse expression of TRP channels in the GI tract and the anatomical distribution pattern of IBD. Differences of microbial composition in certain gut regions and the crosstalk between microbiota and TRP channels are also likely to underlie the IBD anatomical distribution $(6,132)$. Likewise, it is reasonable to hypothesize that the diverse function of TRP channels in immune cells may be responsible for the distinct pathological pattern of $\mathrm{UC}$ and CD. A clear elucidation of this issue can facilitate a better understanding of the TRP channels and pathogenesis involved in IBD.

\section{TRPA1}

The studies regarding the role of TRPA1 in IBD all showed a upregulated TRPA1 expression in the colonic tissue of IBD patients (Table 1). In animal studies, mice with experimental colitis exhibited an increased TRPA1-mediated colonic neuropeptide release, while the experimental colitis appeared to be less severe after the inhibition of TRPA1 by the antagonist or genetic depletion (119). Additional studies suggested a protective role of TRPA1 in the GI tract. Pagano et al. (85) demonstrated that Cannabidivarin, a potent agonist of TRPA1, was able to attenuate the intestinal inflammation in biopsies from pediatric patients with active UC. In dinitrobenzene sulfonic acid (DNBS)- and DSS-treated mice, Cannabidivarin could also ameliorate neutrophil infiltration, intestinal permeability, cytokine production, and alter the dysregulation of gut microbiota (85). Kun et al. (71) reported that the ablation of TRPA1 aggravated DSS-induced colitis and the activation of TRPA1 reduced the release of neuropeptides, cytokines, and chemokines, such as IL-1 $\beta$ and macrophage chemoattractant protein-1 (MCP-1). Further support showed that TRPA1 activation reduced the level of TNF- $\alpha$ in colitis (2). Given that macrophage is the major producer for TNF- $\alpha$, it may be that the TRPA1 in macrophages can suppress the release of TNF- $\alpha$ and modulate the anti-colitogenic effect, albeit the definite mechanism remains unclear. In addition, some evidence indicated that the expression of TRPA1 was increased in colonic stenotic regions of CD patients. The extent of intestinal inflammation and fibrotic changes in TNBS-treated TRPA1 ${ }^{-/-}$ mice were more prominent compare to WT mice and the fibrosis could not be suppressed by inhibitors. The underlying mechanism was considered to be based on the anti-fibrotic role of TRPA1 in intestinal myofibroblasts $(74,75)$. These observations hint a novel therapeutic target to relieve the fibrosis in IBD.

Whilst considering the highly co-expressive nature of TRPV1 and TRPA1 in colonic afferents, it is interesting to shed light on the interaction between TRPV1 and TRPA1 in colitis. A stimulation of TRPA1 in dorsal root ganglia could result in the activation of PKA and subsequent phosphorylation of TRPV1 (133), while the activation of TRPV1 in afferents could desensitize TRPA1 through phosphatidylinosital biphosphate $\left(\mathrm{PIP}_{2}\right)$ depletion (134). In IBD patients, a vast infiltration of TRPV $1^{+}$TRPA $^{+}{ }^{+} \mathrm{T}$ cells had been identified in inflamed colonic tissue (68). Bertin et al. (68) found that TRPV $1^{+} \mathrm{TRPA}^{-} \mathrm{T}$ cells were able to enhance T-cell receptor-induced $\mathrm{Ca}^{2+}$ influx and aggravated intestinal inflammation in IL-10 knockout mice and T-cell-transfer colitis models compared to TRPV $1^{+} \mathrm{TRPA}^{+}{ }^{+} \mathrm{T}$ cells. However, the colitogenic properties of TRPV $1^{+} \mathrm{TRPA}^{-}{ }^{-} \mathrm{T}$ cells were abrogated with pharmacological inhibition or genetic deletion of TRPV1 $(68,117)$, suggesting that TRPA1 inhibited TRPV1 activity in $\mathrm{CD} 4^{+} \mathrm{T}$ cells and consequently restrained the activity of $\mathrm{CD}^{+}{ }^{+} \mathrm{T}$ cells. Thus, the role of TRPA1 in colitis could be either protective or damaging.

\section{TRPV4}

The TRPV4 mRNA expression and TRPV4 immunoreactivity in colon were remarkably upregulated in $\operatorname{IBD}$ patients $(70,72$, 76), in particular, serosal blood vessels with active inflammation were more densely innervated by TRPV4-positive fibers, which often co-localized with the infiltrating $\mathrm{CD} 45^{+}$cells $(73,76)$. Meanwhile, TRPV4 activation could recruit macrophages and other immune cells through the induction of chemokines, such as IL-8 and MCP-1 (73). D'Aldebert et al. (73) indicated the upregulated colonic TRPV4 expression in DSS-treated mice. Intracolonic administration of the TRPV4 agonists (4alphaphorbol-12,13-didecanoate or GSK1016790A) in mice activated $\mathrm{NF}-\kappa \mathrm{B}$ and activator protein 1 (AP-1) signaling pathway, resulting in exacerbated DSS-induced colitis and even transiently increased the paracellular permeability of epithelium and blood vessel, while TRPV4-knockout mice conferred a strong resistance to the colitis $(73,81)$. These results prove the deleterious effects of TRPV4 on mucosal inflammation. Conversely, a systemic or local administration of RN1734, a selective TRPV4 
antagonist, remarkably relieved the TNBS-induced colitis (72), suggesting the benefit of attenuating inflammation through blocking TRPV4. The medications aiming at TRPV4 might be capable of alleviating intestinal inflammation in IBD.

\section{TRPM2}

The expression of TRPM2 in distal colon was increased in TNBStreated rats (90). In Trpm $2^{-/-}$mice, Yamamoto et al. (120) exhibited that the infiltration of immune cells and the severity of intestinal inflammation were ameliorated in DSS-induced colitis. The underlying mechanism might be that the $\mathrm{Ca}^{2+}$ influx was impaired in Trpm $2^{-/-}$macrophages, thus affecting the activation of NF- $\kappa$ B pathway (120). This evidence reminds us that TRPM2 can exert pro-inflammatory effects in the colitis via its essential role in macrophages and NF- $\kappa$ B signaling pathway.

\section{TRPM8}

TRPM8 expression was demonstrated to be upregulated in IBD patients and in DSS- or TNBS-treated mice (77). The activation of TRPM8 with icilin significantly attenuated the experimental colitis, but $\operatorname{Trpm} 8^{-/-}$mice were quite susceptible to colitis $(62,77)$. It was considered that TRPM8 performed its protective role in the intestine via restraining the release of TNF- $\alpha$, IL1, IL-6, and MCP-1, and inducing the release of CGRP (62, 77). TRPM8 activation could also reduce the TRPV1-dependent CGRP release in the gut (77), showing the ability of TRPM8 to suppress the TRPV1-associated inflammatory cascade. The reconstitution of $\operatorname{Trpm} 8^{-/-}$macrophages in mice exerted a deleterious effect on DSS-induced colitis (60), exhibiting a protective property of TRPM8 in macrophages. These findings reinforce the anti-colitogenic function of TRPM8. Agonists for TRPM8 possibly serve as therapeutic strategies for alleviating intestinal inflammation.

\section{POSSIBLE FACTORS BEHIND PRIOR CONTRADICTORY RESULTS}

According to aforementioned researches, the roles of a certain type of TRP channels in IBD and experimental colitis tended to be bidirectional or even conflicting.

The human studies mainly concentrated on the expression of TRP channels in the colonic tissue of IBD patients, however, the results of these studies appeared to be contradictory, especially concerning the expression of TRPV1. Actually, TRP channels are widely but anatomically distinctly distributed in various tissues and cell types in the GI tract (6). The expression and function of TRP channels may also be diverse in different subtypes and phases of IBD, and vary among individuals (79). However, the tissue samples of previous studies were acquired at multiple sites of the GI tract and the sample sizes were relatively small. Therefore, further researches that collect sufficient samples from a certain GI region and separately analyze the expression of TRP channels in UC and CD are warranted. Noteworthy, in IBD genome-wide association studies (GWAS), no single nucleotide polymorphism of TRP channel- related genes has been identified in correlation with IBD (135). However, the functions of TRP channels in the GI tract are tightly associated with the content in
GI lumen and molecules that possess significant polymorphisms in IBD GWAS, such as TLR4 (136). Additional IBD GWAS studies are needed to uncover specific factors including dietary intake or microbiota in IBD patients in order to explore the definite role of TRP channels polymorphisms in IBD.

Amongst the animal studies regarding TRP channels, researches on TRPV1 and TRPA1 were dominated, thus the majority of conflicting data was related to the functions of these two channels in experimental colitis. Many elements were probably responsible for the paradox.

First, the limitations of the animal models and experimental methods applied in the studies should be considered. Unfortunately, the ideal IBD models that completely mimic the multifactorial chronic disease do not exist and the pathophysiological mechanisms underlying different models are diverse. Also, animals of different strains, species, or ages have their distinct susceptibility to the stimulus, resulting in various demonstrations in experimental colitis (137). Due to the variety of animals and colitis models being used in prior studies, the animal models with distinct characteristics per se might accidentally account for the discrepant actions of TRP channels. Meanwhile, the different experimental methodology and drug administration could lead to opposing results. For example, capsaicin, the agonist for TRPV1, has dual effects that the low-dose capsaicin only affects a variable number of TRPV1-expressing nerves, while the high-dose capsaicin results in nerve desensitization (6), indicating the influence of the dose of stimuli on TRP channels. Moreover, the function of TRP channels might be affected by the changes in the microenvironment of the gut induced by agonists or antagonists (138), thus masking the true effects of TRP channels. It was revealed that TRP channels activation could be achieved via overexpression, phosphorylation, or recruitment to the plasma membrane (68). Additional experiments regarding the mode of TRP channels activation induced by specific stimulus may provide a rational view on the interaction between the stimulus and TRP channels.

Second, in addition to the exogenous stimuli applied in studies, there appears to be various endogenous ligands acting on TRP channels, thus influencing the results of experiments. Compounds, such as prostaglandin metabolites, nerve growth factor, and products of oxidative stress can mediate TRPV1 and TRPA1 $(5,95,139)$, making it difficult to attribute the results observed in studies to the stimulation of exogenous chemicals or to the stimulation of endogenous mediators. Actually, besides the administration of exogenous stimuli for TRP channels, the activation of TRP channels in IBD is also based on the stimulating effects of multiple endogenous mediators which are synthesized and released within the progress of colitis. Some of these compounds may potentialize TRP channels via the GPCR pathway (5). Hence, it is likely that TRP channels play a role not only in the initiation but also in the regulation of the intestinal inflammation, while the exact mechanism is unclear and needs further explorations.

Third, the functions of neurogenic inflammation and immune responses triggered by TRP channels activation are complicated. The neurogenic inflammation is featured of the release of 
CGRP and SP, but the effects of these two neuropeptides on intestinal inflammation were not clearly elucidated and tended to be contradictory. The differences in the concentration of neuropeptides and the expression of receptors might contribute to the discrepancy (4). SP was reported to sensitize TRPV1 during colitis and affect the functions of TRPV1 (78), suggesting a possible feedback sensitization loop between neuropeptides and TRP channels. In addition, a range of evidence showed that neuropeptides, such as somatostatin, galanin, opioid peptides, VIP, and PACAP could participate in the inflammation and regulate the inflammatory responses $(130,140)$. It is warranted to explore whether there is an association between these neuropeptides and TRP channels in colitis. As for immunity, besides the TRP channels-expressing immune cells, some nonimmune cells may have TRP channels in the colitis. For example, the expression and function of TRPA1 were identified in fibroblasts which could transform into myofibroblasts and contribute to the regulation of intestinal inflammation (74,
$75,105)$. However, the definite involvement of myofibroblasts in colitis was poorly understood. Additional explorations are necessary to reveal other TRP channels-expressing cells that play a role in colitis.

Fourth, the TRP channels may interact with various cellular pathways. For instance, the inhibition of TRPV1 could lead to an increased availability of anandamide, and then induced downstream effects on NF- $\kappa$ B and TNF- $\alpha$ and affected bowel motility via the receptor for anandamide (78, 124). Meanwhile, anandamide could also act on TRPV1 and regulate a protection against intestinal inflammation (78, 124), suggesting a potential synergy between TRP channels and other cellular pathways in some settings. Similar to the interaction between TRPV1 and TRPA1, the possible crosstalk between other subtypes of TRP channels is also worth noting. Further studies are warranted to elucidate the comprehensive regulatory network induced by the stimulation of TRP channels in colitis.

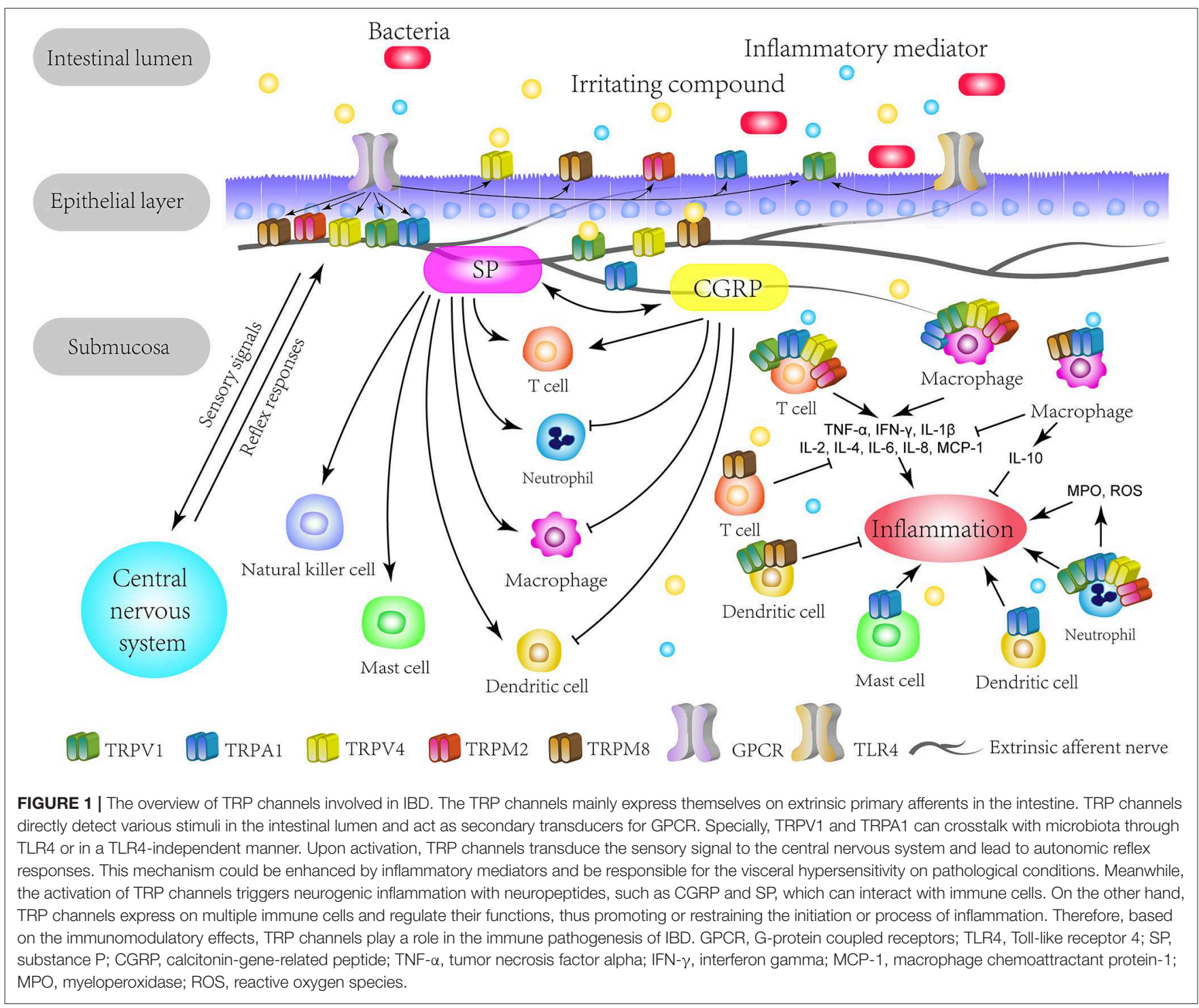


In general, the stimulation of TRP channels and a serial cascade of events are like double-edged swords in the intestinal inflammation that exert colitogenic or anti-colitogenic effects in different situations, influenced by a myriad of interactions amongst stimuli, neuropeptides, and the immunity. It is a challenge to figure out the accurate action of a certain type of TRP channels in a specific immune or cellular pathway. Intriguingly, Cohen et al. (22) applied in vivo optogenetic strategy to selectively stimulate cutaneous $\mathrm{TRPV} 1^{+}$-neuron and showed that the afferent activation was based on a nerve reflex. In this study, the activation of TRPV1 was in the absence of other inflammatory stimuli, thus specifically demonstrating the precise role of TRPV1 in the afferents and its immunity-triggering effects. Considering the intense interactions amongst various factors in previous researches, utilizing novel technologies that can efficiently eliminate interferences is a promising strategy for further studies on TRP channels.

\section{THERAPEUTIC VALUES OF TRP CHANNELS FOR IBD}

As discussed, the effects of TRP channels in IBD have been increasingly appreciated, it is intriguing for researchers to explore their therapeutic values for relieving inflammatory VHS and intestinal inflammation. Pharmacologically, the modulating agents for TRP channels include antagonists and stimulant agonists (141). In particular, antagonists for TRP channels exert a specific effect on modification of ion channel, and stimulant agonists facilitate the desensitization of sensitive afferents (142). However, owing to the wide distribution and various physiological roles of TRP channels within and outside the GI tract (143), the modulation of TRP channels may result in pronounced side effects, such as hyper-thermic effect and impaired injurious-heat perception generated by TRPV1 antagonists $(144,145)$. Therefore, it is vital to develop the stimulus-specific blockers for TRP channels that specifically act on the aberrant function while sparing the physiological function.

Besides targeting TRP channels directly, it is worth noting that aiming at the stimulus and downstream pathways for GPCRs tends to be another valuable method of restraining the action of TRP channels, especially in the inflammatory process. A novel class of endogenous lipid mediators named resolvin, which are generated from immune cells, such as eosinophils and neutrophils, are of particular interest and have the ability to suppress the function of TRP channels including TRPV1, TRPA1, and TRPV4 $(146,147)$. The anti-inflammatory effects of resolvin are likely based on the activation of inhibitory GPCR that subsequently suppresses the GPCR-associated sensitization or activation of TRP channels (148), showing the feasibility for

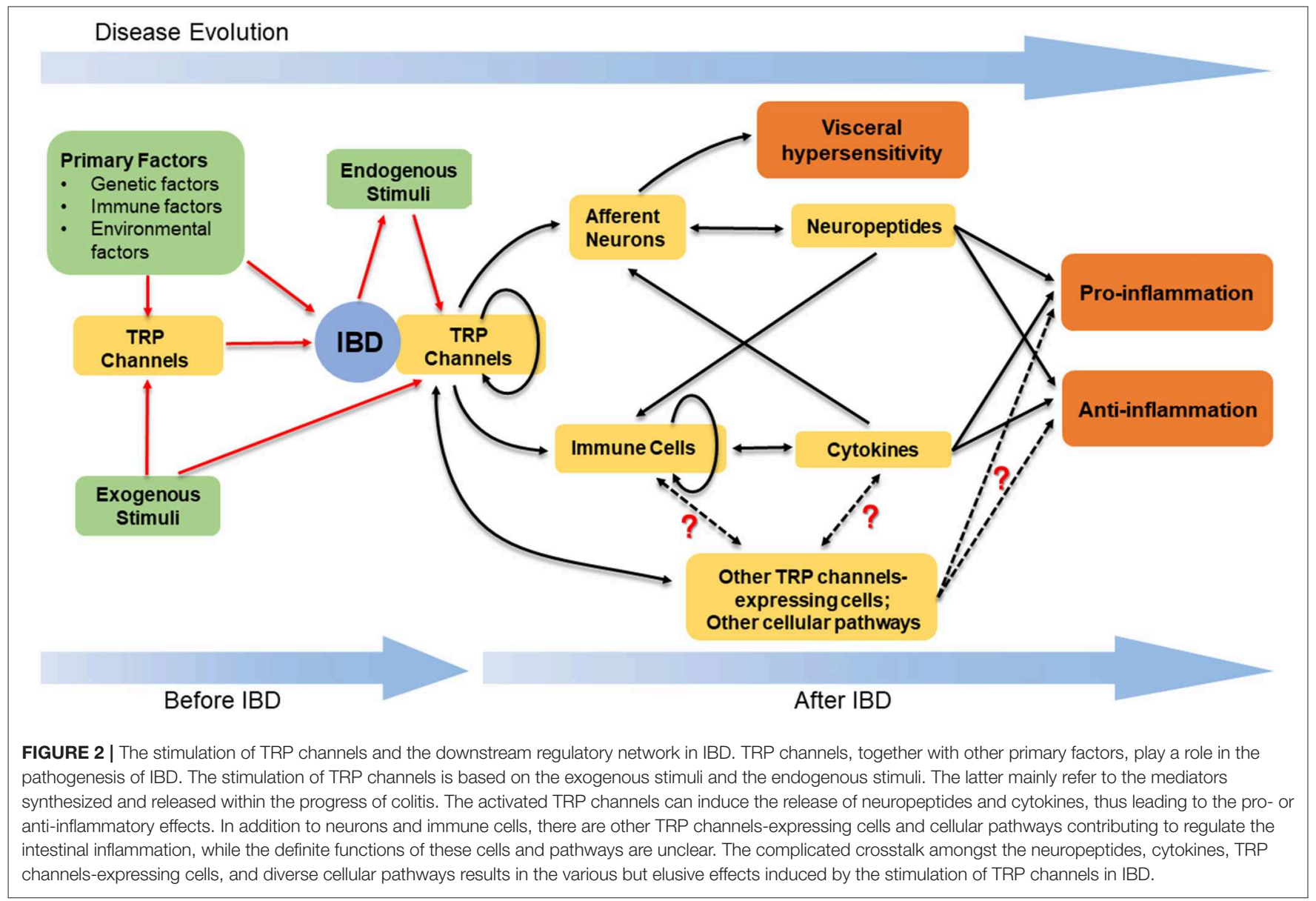


inhibiting TRP channels through regulating GPCRs. Overall, treatment strategies targeting TRP channels and their signaling pathways predict a promising future for alleviating the symptoms and improving the prognosis of IBD. More studies are warranted to identify the efficacy and safety of these therapeutic approaches.

To conclude, TRP channels are not only widely distributed on neurons in the GI tract, functioning as detectors for stimuli and triggers for neurogenic inflammation, but also expressed in multiple immune cells and modulate immune responses (Figure 1). Accumulated evidence has supported an important association between TRP channels and IBD. Although different types of TRP channels exert distinct effects, it is evident that TRP channels are involved in the VHS and the pathogenesis of IBD through a complicated and elusive regulatory network (Figure 2). The inhibition or activation of selected TRP channels can restrain the development of VHS and inflammation in the context of colitis. Therefore, TRP antagonists and agonists tend

\section{REFERENCES}

1. Zhang YZ, Li YY. Inflammatory bowel disease: pathogenesis. World J Gastroenterol. (2014) 20:91-9. doi: 10.3748/wjg.v20.i1.91

2. Khalil M, Alliger K, Weidinger C, Yerinde C, Wirtz S, Becker C, et al. Functional role of transient receptor potential channels in immune cells and epithelia. Front Immunol. (2018) 9:174. doi: 10.3389/fimmu.2018.00174

3. Zheng J. Molecular mechanism of TRP channels. Compr Physiol. (2013) 3:221-42. doi: 10.1002/cphy.c120001

4. Engel MA, Becker C, Reeh PW, Neurath MF. Role of sensory neurons in colitis: increasing evidence for a neuroimmune link in the gut. Inflamm Bowel Dis. (2011) 17:1030-3. doi: 10.1002/ibd.21422

5. Zielinska M, Jarmuz A, Wasilewski A, Salaga M, Fichna J. Role of transient receptor potential channels in intestinal inflammation and visceral pain: novel targets in inflammatory bowel diseases. Inflamm Bowel Dis. (2015) 21:419-27. doi: 10.1097/MIB.0000000000000234

6. Holzer P. Transient receptor potential (TRP) channels as drug targets for diseases of the digestive system. Pharmacol Ther. (2011) 131:14270. doi: 10.1016/j.pharmthera.2011.03.006

7. Inoue R, Kurahara LH, Hiraishi K. TRP channels in cardiac and intestinal fibrosis. Semin Cell Dev Biol. (2019) 94:409. doi: 10.1016/j.semcdb.2018.11.002

8. Yang F, Zheng J. Understand spiciness: mechanism of TRPV1 channel activation by capsaicin. Protein Cell. (2017) 8:16977. doi: 10.1007/s13238-016-0353-7

9. Cseko K, Beckers B, Keszthelyi D, Helyes Z. Role of TRPV1 and TRPA1 ion channels in inflammatory bowel diseases: potential therapeutic targets? Pharmaceuticals. (2019) 12:48. doi: 10.3390/ph12020048

10. Vergnolle N. TRPV4: new therapeutic target for inflammatory bowel diseases. Biochem Pharmacol. (2014) 89:15761. doi: 10.1016/j.bcp.2014.01.005

11. Du Q, Liao Q, Chen C, Yang X, Xie R, Xu J. The role of transient receptor potential vanilloid 1 in common diseases of the digestive tract and the cardiovascular and respiratory system. Front Physiol. (2019) 10:1064. doi: 10.3389/fphys.2019.01064

12. Balemans D, Boeckxstaens GE, Talavera K, Wouters MM. Transient receptor potential ion channel function in sensory transduction and cellular signaling cascades underlying visceral hypersensitivity. Am J Physiol Gastrointest Liver Physiol. (2017) 312: G635-48. doi: 10.1152/ajpgi.00401.2016

13. Veldhuis NA, Poole DP, Grace M, McIntyre P, Bunnett NW. The G proteincoupled receptor-transient receptor potential channel axis: molecular insights for targeting disorders of sensation and inflammation. Pharmacol Rev. (2015) 67:36-73. doi: 10.1124/pr.114.009555 to constitute an attractive target in IBD treatment and need further attention.

\section{AUTHOR CONTRIBUTIONS}

YC and HZ reviewed the literature and outlined the overall manuscript. YC wrote the manuscript. JM and MZ helped to write the manuscript. AM and $\mathrm{HZ}$ revised the manuscript. HZ supervised the preparation of the draft and edited it and worked as a corresponding author. All authors approved the final version.

\section{FUNDING}

This work was supported by National Natural Science Foundation of China [Grant Number: 81570502], and by 1.3.5 Project for disciplines of excellence, West China Hospital, Sichuan University [Grant Number: ZYJC18037].
14. Allais L, De Smet R, Verschuere S, Talavera K, Cuvelier CA, Maes T. Transient receptor potential channels in intestinal inflammation: what is the impact of cigarette smoking? Pathobiology. (2017) 84:115. doi: 10.1159/000446568

15. Sousa-Valente J, Brain SD. A historical perspective on the role of sensory nerves in neurogenic inflammation. Semin Immunopathol. (2018) 40:22936. doi: 10.1007/s00281-018-0673-1

16. Holzmann B. Antiinflammatory activities of CGRP modulating innate immune responses in health and disease. Curr Protein Pept Sci. (2013) 14:268-74. doi: 10.2174/13892037113149990046

17. Assas BM, Miyan JA, Pennock JL. Cross-talk between neural and immune receptors provides a potential mechanism of homeostatic regulation in the gut mucosa. Mucosal Immunol. (2014) 7:1283-9. doi: 10.1038/mi.2014.80

18. Altmayr F, Jusek G, Holzmann B. The neuropeptide calcitonin generelated peptide causes repression of tumor necrosis factor-alpha transcription and suppression of ATF-2 promoter recruitment in Toll-like receptor-stimulated dendritic cells. J Biol Chem. (2010) 285:3525-31. doi: 10.1074/jbc.M109.066787

19. Gomes RN, Castro-Faria-Neto HC, Bozza PT, Soares MB, Shoemaker CB, David JR, et al. Calcitonin gene-related peptide inhibits local acute inflammation and protects mice against lethal endotoxemia. Shock. (2005) 24:590-4. doi: 10.1097/01.shk.0000183395.29014.7c

20. Pinho-Ribeiro FA, Baddal B, Haarsma R, O’Seaghdha M, Yang NJ, Blake $\mathrm{KJ}$, et al. Blocking neuronal signaling to immune cells treats streptococcal invasive infection. Cell. (2018) 173:1083-97. doi: 10.1016/j.cell.2018.04.006

21. Nagashima H, Mahlakoiv T, Shih HY, Davis FP, Meylan F, Huang $\mathrm{Y}$, et al. Neuropeptide CGRP limits group 2 innate lymphoid cell responses and constrains type 2 inflammation. Immunity. (2019) 51:68295.e6. doi: 10.1016/j.immuni.2019.06.009

22. Cohen JA, Edwards TN, Liu AW, Hirai T, Jones MR, Wu J, et al. Cutaneous TRPV1(+) neurons trigger protective innate type 17 anticipatory immunity. Cell. (2019) 178:919-32. doi: 10.1016/j.cell.2019.06.022

23. Talme T, Liu Z, Sundqvist KG. The neuropeptide calcitonin gene-related peptide (CGRP) stimulates $\mathrm{T}$ cell migration into collagen matrices. $J$ Neuroimmunol. (2008) 196:60-6. doi: 10.1016/j.jneuroim.2008.02.007

24. Levite M. Neurotransmitters activate T-cells and elicit crucial functions via neurotransmitter receptors. Curr Opin Pharmacol. (2008) 8:46071. doi: 10.1016/j.coph.2008.05.001

25. Li FJ, Zou YY, Cui Y, Yin Y, Guo G, Lu FG. Calcitonin gene-related peptide is a promising marker in ulcerative colitis. Dig Dis Sci. (2013) 58:68693. doi: 10.1007/s10620-012-2406-y

26. Anand U, Yiangou Y, Akbar A, Quick T, MacQuillan A, Fox M, et al. Glucagon-like peptide 1 receptor (GLP-1R) expression by nerve fibres in 
inflammatory bowel disease and functional effects in cultured neurons. PLoS ONE. (2018) 13:e198024. doi: 10.1371/journal.pone.0198024

27. Bossaller C, Reither K, Hehlert-Friedrich C, Auch-Schwelk W, Graf K, Grafe $\mathrm{M}$, et al. In vivo measurement of endothelium-dependent vasodilation with substance P in man. Herz. (1992) 17:284-90.

28. Schlereth T, Schukraft J, Kramer-Best HH, Geber C, Ackermann T, Birklein F. Interaction of calcitonin gene related peptide (CGRP) and substance P (SP) in human skin. Neuropeptides. (2016) 59:5762. doi: 10.1016/j.npep.2016.06.001

29. Suvas S. Role of substance $P$ neuropeptide in inflammation, wound healing, and tissue homeostasis. J Immunol. (2017) 199:1543-52. doi: 10.4049/jimmunol.1601751

30. Green DP, Limjunyawong N, Gour N, Pundir P, Dong X. A mast-cellspecific receptor mediates neurogenic inflammation and pain. Neuron. (2019) 101:412-20. doi: 10.1016/j.neuron.2019.01.012

31. Zhao D, Kuhnt-Moore S, Zeng H, Pan A, Wu JS, Simeonidis S, et al. Substance P-stimulated interleukin-8 expression in human colonic epithelial cells involves Rho family small GTPases. Biochem J. (2002) 368:66572. doi: $10.1042 /$ bj20020950

32. El-Salhy M, Solomon T, Hausken T, Gilja OH, Hatlebakk JG. Gastrointestinal neuroendocrine peptides/amines in inflammatory bowel disease. World $J$ Gastroenterol. (2017) 23:5068-85. doi: 10.3748/wjg.v23.i28.5068

33. Hong HS, Hwang DY, Park JH, Kim S, Seo EJ, Son Y. Substance-P alleviates dextran sulfate sodium-induced intestinal damage by suppressing inflammation through enrichment of M2 macrophages and regulatory T cells. Cytokine. (2017) 90:21-30. doi: 10.1016/j.cyto.2016.10.002

34. Hwang DY, Kim S, Hong HS. Substance-P ameliorates dextran sodium sulfate-induced intestinal damage by preserving tissue barrier function. Tissue Eng Regen Med. (2018) 15:63-73. doi: 10.1007/s13770-017-0085-7

35. Zhao JF, Ching LC, Kou YR, Lin SJ, Wei J, Shyue SK, et al. Activation of TRPV1 prevents OxLDL-induced lipid accumulation and TNF-alphainduced inflammation in macrophages: role of liver $\mathrm{X}$ receptor alpha. Mediators Inflamm. (2013) 2013:925171. doi: 10.1155/2013/925171

36. Fernandes ES, Liang L, Smillie SJ, Kaiser F, Purcell R, Rivett DW, et al. TRPV1 deletion enhances local inflammation and accelerates the onset of systemic inflammatory response syndrome. J Immunol. (2012) 188:574151. doi: 10.4049/jimmunol.1102147

37. Bertin S, de Jong PR, Jefferies WA, Raz E. Novel immune function for the TRPV1 channel in T lymphocytes. Channels. (2014) 8:47980. doi: $10.4161 / 19336950.2014 .991640$

38. Ghoneum MH, Gimzewski JK, Ghoneum A, Katano H, Paw U CN, Agrawal A. Inhibition of TRPV1 channel activity in human $\mathrm{CD} 4^{+} \mathrm{T}$ cells by nanodiamond and nanoplatinum liquid, DPV576. Nanomaterials (Basel). (2018) 8:770. doi: 10.3390/nano8100770

39. Jaromi P, Garab D, Hartmann P, Bodnar D, Nyiri S, Santha P, et al. Capsaicin-induced rapid neutrophil leukocyte activation in the rat urinary bladder microcirculatory bed. Neurourol Urodyn. (2018) 37:6908. doi: $10.1002 /$ nau. 23376

40. Acharya N, Penukonda S, Shcheglova T, Hagymasi AT, Basu S, Srivastava PK. Endocannabinoid system acts as a regulator of immune homeostasis in the gut. Proc Natl Acad Sci USA. (2017) 114:5005-10. doi: 10.1073/pnas.1612177114

41. Yao E, Zhang G, Huang J, Yang X, Peng L, Huang $X$, et al. Immunomodulatory effect of oleoylethanolamide in dendritic cells via TRPV1/AMPK activation. J Cell Physiol. (2019) 234:18392-407. doi: 10.1002/jcp.28474

42. Baral P, Umans BD, Li L, Wallrapp A, Bist M, Kirschbaum T, et al. Nociceptor sensory neurons suppress neutrophil and $\gamma \delta \mathrm{T}$ cell responses in bacterial lung infections and lethal pneumonia. Nat Med. (2018) 24:41726. doi: $10.1038 / \mathrm{nm} .4501$

43. Sahoo SS, Majhi RK, Tiwari A, Acharya T, Kumar PS, Saha S. Transient receptor potential ankyrin1 channel is endogenously expressed in T cells and is involved in immune functions. Biosci Rep. (2019) 39:BSR20191437. doi: 10.1042/BSR20191437

44. Gouin O, L'Herondelle K, Lebonvallet N, Le Gall-Ianotto C, Sakka M, Buhe V, et al. TRPV 1 and TRPA 1 in cutaneous neurogenic and chronic inflammation: pro-inflammatory response induced by their activation and their sensitization. Protein Cell. (2017) 8:644-61. doi: 10.1007/s13238-017-0395-5
45. Zhou Y, Han D, Follansbee T, Wu X, Yu S, Wang B, et al. Transient receptor potential ankyrin 1 (TRPA1) positively regulates imiquimodinduced, psoriasiform dermal inflammation in mice. J Cell Mol Med. (2019) 23:4819-28. doi: $10.1111 / \mathrm{jcmm} .14392$

46. Romano B, Borrelli F, Fasolino I, Capasso R, Piscitelli F, Cascio M, et al. The cannabinoid TRPA1 agonist cannabichromene inhibits nitric oxide production in macrophages and ameliorates murine colitis. $\mathrm{Br} J$ Pharmacol. (2013) 169:213-29. doi: 10.1111/bph.12120

47. Diogenes A, Ferraz CC, Akopian AN, Henry MA, Hargreaves KM. LPS sensitizes TRPV1 via activation of TLR4 in trigeminal sensory neurons. $J$ Dent Res. (2011) 90:759-64. doi: 10.1177/0022034511400225

48. De Winter BY, Bredenoord AJ, Van Nassauw L, De Man JG, De Schepper HU, Timmermans JP, et al. Involvement of afferent neurons in the pathogenesis of endotoxin-induced ileus in mice: role of CGRP and TRPV1 receptors. Eur J Pharmacol. (2009) 615:177-84. doi: 10.1016/j.ejphar.2009.04.055

49. Perez-Burgos A, Wang L, McVey NK, Mao YK, Ahmadzai M, Janssen LJ, et al. The TRPV1 channel in rodents is a major target for antinociceptive effect of the probiotic Lactobacillus reuteri DSM 17938. J Physiol. (2015) 593:3943-57. doi: 10.1113/JP270229

50. Meseguer V, Alpizar YA, Luis E, Tajada S, Denlinger B, Fajardo $O$, et al. TRPA1 channels mediate acute neurogenic inflammation and pain produced by bacterial endotoxins. Nat commun. (2014) 5:3125. doi: $10.1038 /$ ncomms 4125

51. Li M, Fang XZ, Zheng YF, Xie YB, Ma XD, Liu XT, et al. Transient receptor potential vanilloid 4 is a critical mediator in LPS mediated inflammation by mediating calcineurin/NFATc3 signaling. Biochem Biophys Res Commun. (2019) 513:1005-12. doi: 10.1016/j.bbrc.2019.04.020

52. Scheraga RG, Abraham S, Niese KA, Southern BD, Grove LM, Hite RD, et al. TRPV4 mechanosensitive ion channel regulates lipopolysaccharide-stimulated macrophage phagocytosis. I Immunol. (2016) 196:428-36. doi: 10.4049/jimmunol.1501688

53. Yin J, Michalick L, Tang C, Tabuchi A, Goldenberg N, Dan Q, et al. Role of transient receptor potential vanilloid 4 in neutrophil activation and acute lung injury. Am J Respir Cell Mol Biol. (2016) 54:37083. doi: $10.1165 / \mathrm{rcmb}$.2014-0225OC

54. Majhi RK, Sahoo SS, Yadav M, Pratheek BM, Chattopadhyay S, Goswami C. Functional expression of TRPV channels in T cells and their implications in immune regulation. FEBS J. (2015) 282:2661-81. doi: 10.1111/febs. 13306

55. Naert R, Lopez-Requena A, Voets T, Talavera K, Alpizar YA. Expression and functional role of TRPV4 in bone marrow-derived CD11c(+) cells. Int J Mol Sci. (2019) 20:3378. doi: 10.3390/ijms20143378

56. Wehrhahn J, Kraft R, Harteneck C, Hauschildt S. Transient receptor potential melastatin 2 is required for lipopolysaccharide-induced cytokine production in human monocytes. J Immunol. (2010) 184:2386-93. doi: 10.4049/jimmunol.0902474

57. Gershkovitz M, Caspi Y, Fainsod-Levi T, Katz B, Michaeli J, Khawaled S, et al. TRPM2 mediates neutrophil killing of disseminated tumor cells. Cancer Res. (2018) 78:2680-90. doi: 10.1158/0008-5472.CAN-17-3614

58. Mittal M, Nepal S, Tsukasaki Y, Hecquet CM, Soni D, Rehman J, et al. Neutrophil activation of endothelial cell-expressed TRPM2 mediates transendothelial neutrophil migration and vascular injury. Circ Res. (2017) 121:1081-91. doi: 10.1161/CIRCRESAHA.117.311747

59. Melzer N, Hicking G, Gobel K, Wiendl H. TRPM2 cation channels modulate $\mathrm{T}$ cell effector functions and contribute to autoimmune CNS inflammation. PLoS ONE. (2012) 7:e47617. doi: 10.1371/journal.pone.0047617

60. Khalil M, Babes A, Lakra R, Forsch S, Reeh PW, Wirtz S, et al. Transient receptor potential melastatin 8 ion channel in macrophages modulates colitis through a balance-shift in TNF-alpha and interleukin-10 production. Mucosal immunol. (2016) 9:1500-13. doi: 10.1038/mi.2016.16

61. Juergens UR, Engelen T, Racke K, Stober M, Gillissen A, Vetter H. Inhibitory activity of 1,8-cineol (eucalyptol) on cytokine production in cultured human lymphocytes and monocytes. Pulm Pharmacol Ther. (2004) 17:281-7. doi: 10.1016/j.pupt.2004.06.002

62. de Jong PR, Takahashi N, Peiris M, Bertin S, Lee J, Gareau MG, et al. TRPM8 on mucosal sensory nerves regulates colitogenic responses by innate immune cells via CGRP. Mucosal Immunol. (2015) 8:491504. doi: $10.1038 / \mathrm{mi} .2014 .82$ 
63. Kume H, Tsukimoto M. TRPM8 channel inhibitor AMTB suppresses murine T-cell activation induced by T-cell receptor stimulation, concanavalin A, or external antigen re-stimulation. Biochem Biophys Res Commun. (2019) 509:918-24. doi: 10.1016/j.bbrc.2019.01.004

64. Akbar A, Yiangou Y, Facer P, Brydon WG, Walters JR, Anand P, et al. Expression of the TRPV1 receptor differs in quiescent inflammatory bowel disease with or without abdominal pain. Gut. (2010) 59:76774. doi: 10.1136/gut.2009.194449

65. Luo C, Wang Z, Mu J, Zhu M, Zhen Y, Zhang H. Upregulation of the transient receptor potential vanilloid 1 in colonic epithelium of patients with active inflammatory bowel disease. Int J Clin Exp Pathol. (2017) 10:11335-44.

66. Yiangou Y, Facer P, Dyer NH, Chan CL, Knowles C, Williams NS, et al. Vanilloid receptor 1 immunoreactivity in inflamed human bowel. Lancet. (2001) 357:1338-39. doi: 10.1016/S0140-6736(00)04503-7

67. Toledo-Maurino JJ, Furuzawa-Carballeda J, Villeda-Ramirez MA, FonsecaCamarillo G, Meza-Guillen D, Barreto-Zuniga R, et al. The transient receptor potential vanilloid 1 is associated with active inflammation in ulcerative colitis. Mediators Inflamm. (2018) 2018:6570371. doi: 10.1155/2018/6570371

68. Bertin S, Aoki-Nonaka Y, Lee J, de Jong PR, Kim P, Han T, et al. The TRPA1 ion channel is expressed in CD4+ T cells and restrains Tcell-mediated colitis through inhibition of TRPV1. Gut. (2017) 66:158496. doi: 10.1136/gutjnl-2015-310710

69. Keszthelyi D, Troost FJ, Jonkers DM, Helyes Z, Hamer HM, Ludidi S, et al. Alterations in mucosal neuropeptides in patients with irritable bowel syndrome and ulcerative colitis in remission: a role in pain symptom generation? Eur J Pain. (2013) 17:1299-306. doi: 10.1002/j.1532-2149.2013.00309.x

70. Rizopoulos T, Papadaki-Petrou H, Assimakopoulou M. Expression profiling of the transient receptor potential vanilloid (TRPV) channels 1, 2, 3 and 4 in mucosal epithelium of human ulcerative colitis. Cells. (2018) 7:61. doi: 10.3390/cells7060061

71. Kun J, Szitter I, Kemeny A, Perkecz A, Kereskai L, Pohoczky K, et al. Upregulation of the transient receptor potential ankyrin 1 ion channel in the inflamed human and mouse colon and its protective roles. PLoS ONE. (2014) 9:e108164. doi: 10.1371/journal.pone.0108164

72. Fichna J, Mokrowiecka A, Cygankiewicz AI, Zakrzewski PK, MaleckaPanas E, Janecka A, et al. Transient receptor potential vanilloid 4 blockade protects against experimental colitis in mice: a new strategy for inflammatory bowel diseases treatment? Neurogastroenterol Motil. (2012) 24:e557-60. doi: 10.1111/j.1365-2982.2012.01999.x

73. D’Aldebert E, Cenac N, Rousset P, Martin L, Rolland C, Chapman K, et al. Transient receptor potential vanilloid 4 activated inflammatory signals by intestinal epithelial cells and colitis in mice. Gastroenterology. (2011) 140:275-85. doi: 10.1053/j.gastro.2010.09.045

74. Hiraishi K, Kurahara LH, Sumiyoshi M, Hu YP, Koga K, Onitsuka M, et al. Daikenchuto (Da-Jian-Zhong-Tang) ameliorates intestinal fibrosis by activating myofibroblast transient receptor potential ankyrin 1 channel. World J Gastroenterol. (2018) 24:4036-53. doi: 10.3748/wjg.v24.i35.4036

75. Kurahara LH, Hiraishi K, Hu Y, Koga K, Onitsuka M, Doi M, et al. Activation of myofibroblast TRPA1 by steroids and pirfenidone ameliorates fibrosis in experimental Crohn's disease. Cell Mol Gastroenterol Hepatol. (2018) 5:299-318. doi: 10.1016/j.jcmgh.2017.12.005

76. Brierley SM, Page AJ, Hughes PA, Adam B, Liebregts T, Cooper NJ, et al. Selective role for TRPV4 ion channels in visceral sensory pathways. Gastroenterology. (2008) 134:2059-69. doi: 10.1053/j.gastro.2008.01.074

77. Ramachandran R, Hyun E, Zhao L, Lapointe TK, Chapman K, Hirota $\mathrm{CL}$, et al. TRPM8 activation attenuates inflammatory responses in mouse models of colitis. Proc Natl Acad Sci USA. (2013) 110:747681. doi: $10.1073 /$ pnas. 1217431110

78. Lapointe TK, Basso L, Iftinca MC, Flynn R, Chapman K, Dietrich G, et al. TRPV1 sensitization mediates postinflammatory visceral pain following acute colitis. Am J Physiol Gastrointest Liver Physiol. (2015) 309:G8799. doi: 10.1152/ajpgi.00421.2014

79. Engel MA, Khalil M, Mueller-Tribbensee SM, Becker C, Neuhuber WL, Neurath MF, et al. The proximodistal aggravation of colitis depends on substance $\mathrm{P}$ released from TRPV1-expressing sensory neurons. J Gastroenterol. (2012) 47:256-65. doi: 10.1007/s00535-011-0495-6
80. Matsumoto K, Lo MW, Hosoya T, Tashima K, Takayama H, Murayama T, et al. Experimental colitis alters expression of 5-HT receptors and transient receptor potential vanilloid 1 leading to visceral hypersensitivity in mice. $L a b$ Invest. (2012) 92:769-82. doi: 10.1038/labinvest.2012.14

81. Matsumoto K, Yamaba R, Inoue K, Utsumi D, Tsukahara T, Amagase $\mathrm{K}$, et al. Transient receptor potential vanilloid 4 channel regulates vascular endothelial permeability during colonic inflammation in dextran sulphate sodium-induced murine colitis. Br J Pharmacol. (2018) 175:8499. doi: 10.1111/bph.14072

82. Hosoya T, Matsumoto K, Tashima K, Nakamura H, Fujino H, Murayama $\mathrm{T}$, et al. TRPM8 has a key role in experimental colitis-induced visceral hyperalgesia in mice. Neurogastroenterol Motil. (2014) 26:111221. doi: $10.1111 / \mathrm{nmo} .12368$

83. Yang M, Wang J, Yang C, Han H, Rong W, Zhang G. Oral administration of curcumin attenuates visceral hyperalgesia through inhibiting phosphorylation of TRPV1 in rat model of ulcerative colitis. Mol Pain. (2017) 13:2071437104. doi: 10.1177/1744806917726416

84. Wu Y, Wang Y, Wang J, Fan Q, Zhu J, Yang L, et al. TLR4 mediates upregulation and sensitization of TRPV1 in primary afferent neurons in 2,4,6-trinitrobenzene sulfate-induced colitis. Mol pain. (2019) 15:2069333502. doi: 10.1177/1744806919830018

85. Pagano E, Romano B, Iannotti FA, Parisi OA, D’Armiento M, Pignatiello $S$, et al. The non-euphoric phytocannabinoid cannabidivarin counteracts intestinal inflammation in mice and cytokine expression in biopsies from UC pediatric patients. Pharmacol Res. (2019) 149:104464. doi: 10.1016/j.phrs.2019.104464

86. Miranda A, Nordstrom E, Mannem A, Smith C, Banerjee B, Sengupta JN. The role of transient receptor potential vanilloid 1 in mechanical and chemical visceral hyperalgesia following experimental colitis. Neuroscience. (2007) 148:1021-32. doi: 10.1016/j.neuroscience.2007.05.034

87. Salameh E, Meleine M, Gourcerol G, Do RJ, Do RJ, Legrand R, et al. Chronic colitis-induced visceral pain is associated with increased anxiety during quiescent phase. Am J Physiol Gastrointest Liver Physiol. (2019) 316:G692-700. doi: 10.1152/ajpgi.00248.2018

88. Yang J, Li Y, Zuo X, Zhen Y, Yu Y, Gao L. Transient receptor potential ankyrin-1 participates in visceral hyperalgesia following experimental colitis. Neurosci Lett. (2008) 440:237-41. doi: 10.1016/j.neulet.2008.05.093

89. Li Q, Guo CH, Chowdhury MA, Dai TL, Han W. TRPA1 in the spinal dorsal horn is involved in post-inflammatory visceral hypersensitivity: in vivo study using TNBS-treated rat model. J Pain Res. (2016) 9:115360. doi: $10.2147 /$ JPR.S118581

90. Matsumoto K, Takagi K, Kato A, Ishibashi T, Mori Y, Tashima K, et al. Role of transient receptor potential melastatin 2 (TRPM2) channels in visceral nociception and hypersensitivity. Exp Neurol. (2016) 285:4150. doi: 10.1016/j.expneurol.2016.09.001

91. Kimball ES, Prouty SP, Pavlick KP, Wallace NH, Schneider CR, Hornby PJ. Stimulation of neuronal receptors, neuropeptides and cytokines during experimental oil of mustard colitis. Neurogastroenterol Motil. (2007) 19:390400. doi: 10.1111/j.1365-2982.2007.00939.x

92. Makimura Y, Ito K, Kuwahara M, Tsubone H. Augmented activity of the pelvic nerve afferent mediated by TRP channels in dextran sulfate sodium (DSS)-induced colitis of rats. J Vet Med Sci. (2012) 74:100713. doi: 10.1292/jvms.11-0547

93. Phillis BD, Martin CM, Kang D, Larsson H, Lindstrom EA, Martinez $\mathrm{V}$, et al. Role of TRPV1 in high-threshold rat colonic splanchnic afferents is revealed by inflammation. Neurosci Lett. (2009) 459:5761. doi: 10.1016/j.neulet.2009.04.051

94. Mitrovic M, Shahbazian A, Bock E, Pabst MA, Holzer P. Chemo-nociceptive signalling from the colon is enhanced by mild colitis and blocked by inhibition of transient receptor potential ankyrin 1 channels. Br J Pharmacol. (2010) 160:1430-42. doi: 10.1111/j.1476-5381.2010.00794.X

95. Kogure Y, Wang S, Tanaka K, Hao Y, Yamamoto S, Nishiyama N, et al. Elevated $\mathrm{H} 2 \mathrm{O} 2$ levels in trinitrobenzene sulfate-induced colitis rats contributes to visceral hyperalgesia through interaction with the transient receptor potential ankyrin 1 cation channel. J Gastroenterol Hepatol. (2016) 31:1147-53. doi: 10.1111/jgh.13226

96. Vermeulen W, De Man JG, De Schepper HU, Bult H, Moreels TG, Pelckmans PA, et al. Role of TRPV1 and TRPA1 in visceral hypersensitivity to colorectal 
distension during experimental colitis in rats. Eur J Pharmacol. (2013) 698:404-12. doi: 10.1016/j.ejphar.2012.10.014

97. Brierley SM, Hughes PA, Page AJ, Kwan KY, Martin CM, O’Donnell TA, et al. The ion channel TRPA1 is required for normal mechanosensation and is modulated by algesic stimuli. Gastroenterology. (2009) 137:208495. doi: 10.1053 /j.gastro.2009.07.048

98. Cattaruzza F, Spreadbury I, Miranda-Morales M, Grady EF, Vanner S, Bunnett NW. Transient receptor potential ankyrin-1 has a major role in mediating visceral pain in mice. Am J Physiol Gastrointest Liver Physiol. (2010) 298:G81-91. doi: 10.1152/ajpgi.00221.2009

99. Grant AD, Cottrell GS, Amadesi S, Trevisani M, Nicoletti P, Materazzi S, et al. Protease-activated receptor 2 sensitizes the transient receptor potential vanilloid 4 ion channel to cause mechanical hyperalgesia in mice. J Physiol. (2007) 578:715-33. doi: 10.1113/jphysiol.2006.121111

100. Mueller-Tribbensee SM, Karna M, Khalil M, Neurath MF, Reeh PW, Engel MA. Differential contribution of TRPA1, TRPV4 and TRPM8 to colonic nociception in mice. PLoS ONE. (2015) 10:e128242. doi: 10.1371/journal.pone.0128242

101. Harrington AM, Hughes PA, Martin CM, Yang J, Castro J, Isaacs NJ, et al. A novel role for TRPM8 in visceral afferent function. Pain. (2011) 152:145968. doi: 10.1016/j.pain.2011.01.027

102. Adam B, Liebregts T, Best J, Bechmann L, Lackner C, Neumann J, et al. A combination of peppermint oil and caraway oil attenuates the postinflammatory visceral hyperalgesia in a rat model. Scand J Gastroenterol. (2006) 41:155-60. doi: 10.1080/00365520500206442

103. Vecchi BL, Marcuzzi A, Tricarico PM, Zanin V, Girardelli M, Bianco AM. Curcumin and inflammatory bowel disease: potential and limits of innovative treatments. Molecules. (2014) 19:21127-53. doi: 10.3390/molecules 191221127

104. Jones RR, Xu L, Gebhart GF. The mechanosensitivity of mouse colon afferent fibers and their sensitization by inflammatory mediators require transient receptor potential vanilloid 1 and acid-sensing ion channel 3. J Neurosci. (2005) 25:10981-9. doi: 10.1523/JNEUROSCI.0703-05.2005

105. Yang Y, Wang S, Kobayashi K, Hao Y, Kanda H, Kondo T, et al. TRPA1expressing lamina propria mesenchymal cells regulate colonic motility. JCI Insight. (2019) 4:e122402. doi: 10.1172/jci.insight.122402

106. Feng CC, Yan XJ, Chen X, Wang EM, Liu Q, Zhang LY, et al. Vagal anandamide signaling via cannabinoid receptor 1 contributes to luminal 5-HT modulation of visceral nociception in rats. Pain. (2014) 155:1591604. doi: 10.1016/j.pain.2014.05.005

107. Cenac N, Altier C, Chapman K, Liedtke W, Zamponi G, Vergnolle $\mathrm{N}$. Transient receptor potential vanilloid-4 has a major role in visceral hypersensitivity symptoms. Gastroenterology. (2008) 135:937-46, 9416. doi: 10.1053/j.gastro.2008.05.024

108. Cenac N, Altier C, Motta JP, D’Aldebert E, Galeano S, Zamponi GW, et al. Potentiation of TRPV4 signalling by histamine and serotonin: an important mechanism for visceral hypersensitivity. Gut. (2010) 59:4818. doi: 10.1136/gut.2009.192567

109. Zhang X, Mak S, Li L, Parra A, Denlinger B, Belmonte C, et al. Direct inhibition of the cold-activated TRPM8 ion channel by Galphaq. Nat Cell Biol. (2012) 14:851-8. doi: 10.1038/ncb2529

110. Kihara N, de la Fuente SG, Fujino K, Takahashi T, Pappas TN, Mantyh CR. Vanilloid receptor-1 containing primary sensory neurones mediate dextran sulphate sodium induced colitis in rats. Gut. (2003) 52:7139. doi: $10.1136 /$ gut.52.5.713

111. Kimball ES, Wallace NH, Schneider CR, D’Andrea MR, Hornby PJ. Vanilloid receptor 1 antagonists attenuate disease severity in dextran sulphate sodium-induced colitis in mice. Neurogastroenterol Motil. (2004) 16:8118. doi: 10.1111/j.1365-2982.2004.00549.x

112. Fujino K, Fuente SGDL, Pappas TN, Mantyh CR. Dextran sulfate sodiuminduced enterocolitis is attenuated in vanilloid receptor-1 knockout mice. Gastroenterology. (2003) 124:A141-2. doi: 10.1016/S0016-5085(03)80700-X

113. Szitter I, Pozsgai G, Sandor K, Elekes K, Kemeny A, Perkecz A, et al. The role of transient receptor potential vanilloid 1 (TRPV1) receptors in dextran sulfate-induced colitis in mice. J Mol Neurosci. (2010) 42:808. doi: $10.1007 / \mathrm{s} 12031-010-9366-5$

114. Utsumi D, Matsumoto $\mathrm{K}$, Tsukahara $\mathrm{T}$, Amagase $\mathrm{K}$, Tominaga $\mathrm{M}$, Kato S. Transient receptor potential vanilloid 1 and transient receptor potential ankyrin 1 contribute to the progression of colonic inflammation in dextran sulfate sodium-induced colitis in mice: Links to calcitonin gene-related peptide and substance P. J Pharmacol Sci. (2018) 136:12132. doi: 10.1016/j.jphs.2017.12.012

115. Fujino K, Takami Y, de la Fuente SG, Ludwig KA, Mantyh CR. Inhibition of the vanilloid receptor subtype-1 attenuates TNBS-colitis. J Gastrointest Surg. (2004) 8:842-7, 847-8. doi: 10.1016/j.gassur.2004.07.011

116. McVey DC, Vigna SR. The capsaicin VR1 receptor mediates substance $\mathrm{P}$ release in toxin A-induced enteritis in rats. Peptides. (2001) 22:143946. doi: 10.1016/S0196-9781(01)00463-6

117. Bertin S, Aoki-Nonaka Y, de Jong PR, Nohara LL, Xu H, Stanwood SR, et al. The ion channel TRPV1 regulates the activation and proinflammatory properties of CD4(+) T cells. Nat Immunol. (2014) 15:1055-63. doi: 10.1038/ni.3009

118. Gad M, Pedersen AE, Kristensen NN, Fernandez CF, Claesson MH. Blockage of the neurokinin 1 receptor and capsaicin-induced ablation of the enteric afferent nerves protect SCID mice against T-cell-induced chronic colitis. Inflamm Bowel Dis. (2009) 15:1174-82. doi: 10.1002/ibd.20902

119. Engel MA, Leffler A, Niedermirtl F, Babes A, Zimmermann K, Filipovic MR, et al. TRPA1 and substance P mediate colitis in mice. Gastroenterology. (2011) 141:1346-58. doi: 10.1053/j.gastro.2011.07.002

120. Yamamoto S, Shimizu S, Kiyonaka S, Takahashi N, Wajima T, Hara Y, et al. TRPM2-mediated $\mathrm{Ca} 2+$ influx induces chemokine production in monocytes that aggravates inflammatory neutrophil infiltration. Nat Med. (2008) 14:738-47. doi: 10.1038/nm1758

121. Okayama M, Tsubouchi R, Kato S, Takeuchi K. Protective effect of lafutidine, a novel histamine $\mathrm{H} 2$-receptor antagonist, on dextran sulfate sodium-induced colonic inflammation through capsaicin-sensitive afferent neurons in rats. Dig Dis Sci. (2004) 49:1696-704. doi: 10.1023/B:DDAS.0000043389.96490.76

122. Evangelista S, Tramontana M. Involvement of calcitonin gene-related peptide in rat experimental colitis. J Physiol Paris. (1993) 87:27780. doi: 10.1016/0928-4257(93)90017-N

123. Goso C, Evangelista S, Tramontana M, Manzini S, Blumberg PM, Szallasi A. Topical capsaicin administration protects against trinitrobenzene sulfonic acid-induced colitis in the rat. Eur J Pharmacol. (1993) 249:18590. doi: 10.1016/0014-2999(93)90431-G

124. Massa F, Sibaev A, Marsicano G, Blaudzun H, Storr M, Lutz B. Vanilloid receptor (TRPV1)-deficient mice show increased susceptibility to dinitrobenzene sulfonic acid induced colitis. J Mol Med. (2006) 84:1426. doi: 10.1007/s00109-005-0016-2

125. Barada KA, Kafrouni MI, Khoury CI, Saade NE, Mourad FH, Szabo SS, et al. Experimental colitis decreases rat jejunal amino acid absorption: role of capsaicin sensitive primary afferents. Life sci. (2001) 69:312131. doi: 10.1016/S0024-3205(01)01418-7

126. Lee J, Yamamoto T, Kuramoto H, Kadowaki M. TRPV1 expressing extrinsic primary sensory neurons play a protective role in mouse oxazolone-induced colitis. Auton Neurosci. (2012) 166:72-6. doi: 10.1016/j.autneu.2011.07.008

127. Reinshagen M, Patel A, Sottili M, Nast C, Davis W, Mueller K, et al. Protective function of extrinsic sensory neurons in acute rabbit experimental colitis. Gastroenterology. (1994) 106:1208-14. doi: 10.1016/0016-5085(94)90011-6

128. Claesson MH. Limited effect of capsaicin in T-cell transfer colitis. Inflamm Bowel Dis. (2011) 17:E121. doi: 10.1002/ibd.21789

129. Reinshagen M, Patel A, Sottili M, French S, Sternini C, Eysselein VE. Action of sensory neurons in an experimental at colitis model of injury and repair. Am J Physiol. (1996) 270:G79-86. doi: 10.1152/ajpgi.1996.270.1.G79

130. Vinuesa AG, Sancho R, Garcia-Limones C, Behrens A, Ten DP, Calzado $\mathrm{MA}$, et al. Vanilloid receptor-1 regulates neurogenic inflammation in colon and protects mice from colon cancer. Cancer Res. (2012) 72:170516. doi: 10.1158/0008-5472.CAN-11-3693

131. Matsumoto K, Kurosawa E, Terui H, Hosoya T, Tashima K, Murayama $\mathrm{T}$, et al. Localization of TRPV1 and contractile effect of capsaicin in mouse large intestine: high abundance and sensitivity in rectum and distal colon. Am J Physiol Gastrointest Liver Physiol. (2009) 297:G34860. doi: 10.1152/ajpgi.90578.2008

132. Bilotta AJ, Cong Y. Gut microbiota metabolite regulation of host defenses at mucosal surfaces: implication in precision medicine. Precis Clin Med. (2019) 2:110-9. doi: 10.1093/pcmedi/pbz008 
133. Spahn V, Stein C, Zollner C. Modulation of transient receptor vanilloid 1 activity by transient receptor potential ankyrin 1. Mol Pharmacol. (2014) 85:335-44. doi: 10.1124/mol.113.088997

134. Akopian AN, Ruparel NB, Jeske NA, Hargreaves KM. Transient receptor potential TRPA1 channel desensitization in sensory neurons is agonist dependent and regulated by TRPV1-directed internalization. J Physiol. (2007) 583:175-93. doi: 10.1113/jphysiol.2007.133231

135. Jostins L, Ripke S, Weersma RK, Duerr RH, McGovern DP, Hui $\mathrm{KY}$, et al. Host-microbe interactions have shaped the genetic architecture of inflammatory bowel disease. Nature. (2012) 491:119-24. doi: 10.1038/nature11582

136. Ao R, Wang Y, Zhnag DR, Du YQ. Role of TLR4 rs4986790A $>$ G and rs4986791C $>$ T polymorphisms in the risk of inflammatory bowel disease. Gastroenterol Res Pract. (2015) 2015:141070. doi: 10.1155/2015/141070

137. Krieglstein CF, Cerwinka WH, Laroux FS, Salter JW, Russell JM, Schuermann G, et al. Regulation of murine intestinal inflammation by reactive metabolites of oxygen and nitrogen: divergent roles of superoxide and nitric oxide. J Exp Med. (2001) 194:1207-18. doi: 10.1084/jem.194.9.1207

138. Belmaati MS, Diemer S, Hvarness T, Baumann K, Pedersen AE, Christensen RE, et al. Antiproliferative effects of TRPV1 ligands on nonspecific and enteroantigen-specific T cells from wild-type and Trpv1 KO mice. Inflamm Bowel Dis. (2014) 20:1004-14. doi: 10.1097/MIB.0000000000000039

139. Akbar A, Yiangou Y, Facer P, Walters JR, Anand P, Ghosh S. Increased capsaicin receptor TRPV1-expressing sensory fibres in irritable bowel syndrome and their correlation with abdominal pain. Gut. (2008) 57:9239. doi: 10.1136/gut.2007.138982

140. Banvolgyi A, Palinkas L, Berki T, Clark N, Grant AD, Helyes Z, et al. Evidence for a novel protective role of the vanilloid TRPV1 receptor in a cutaneous contact allergic dermatitis model. J Neuroimmunol. (2005) 169:86-96. doi: 10.1016/j.jneuroim.2005.08.012

141. Baraldi PG, Preti D, Materazzi S, Geppetti P. Transient receptor potential ankyrin 1 (TRPA1) channel as emerging target for novel analgesics and anti-inflammatory agents. J Med Chem. (2010) 53:5085107. doi: 10.1021/jm100062h
142. Szallasi A, Cortright DN, Blum CA, Eid SR. The vanilloid receptor TRPV1: 10 years from channel cloning to antagonist proof-of-concept. Nat Rev Drug Discov. (2007) 6:357-72. doi: 10.1038/nrd2280

143. Wu LJ, Sweet TB, Clapham DE. International union of basic and clinical pharmacology. LXXVI. Current progress in the mammalian TRP ion channel family. Pharmacol Rev. (2010) 62:381-404. doi: 10.1124/pr.110. 002725

144. Wong GY, Gavva NR. Therapeutic potential of vanilloid receptor TRPV1 agonists and antagonists as analgesics: Recent advances and setbacks. Brain Res Rev. (2009) 60:267-77. doi: 10.1016/j.brainresrev.2008.12.006

145. Voight EA, Kort ME. Transient receptor potential vanilloid-1 antagonists: a survey of recent patent literature. Expert Opin Ther Pat. (2010) 20:110722. doi: 10.1517/13543776.2010.497756

146. Xu ZZ, Zhang L, Liu T, Park JY, Berta T, Yang R, et al. Resolvins RvE1 and RvD1 attenuate inflammatory pain via central and peripheral actions. Nat Med. (2010) 16:592-7, 1-597. doi: 10.1038/nm.2123

147. Serhan CN. Pro-resolving lipid mediators are leads for resolution physiology. Nature. (2014) 510:92-101. doi: 10.1038/nature13479

148. Williams JT, Ingram SL, Henderson G, Chavkin C, von Zastrow M, Schulz S, et al. Regulation of $\mu$-opioid receptors: desensitization, phosphorylation, internalization, and tolerance. Pharmacol Rev. (2013) 65:223-54. doi: 10.1124/pr.112.005942

Conflict of Interest: The authors declare that the research was conducted in the absence of any commercial or financial relationships that could be construed as a potential conflict of interest.

Copyright (c) 2020 Chen, Mu, Zhu, Mukherjee and Zhang. This is an open-access article distributed under the terms of the Creative Commons Attribution License (CC $B Y)$. The use, distribution or reproduction in other forums is permitted, provided the original author(s) and the copyright owner(s) are credited and that the original publication in this journal is cited, in accordance with accepted academic practice. No use, distribution or reproduction is permitted which does not comply with these terms. 